NASA Technical Memorandum 103706 AIAA-91-0777

\title{
A Summary of Existing and Planned Experiment Hardware for Low- Gravity Fluids Research
}

Myron E. Hill and Terence F. O'Malley

Lewis Research Center

Cleveland, Ohio

Prepared for the

29th Aerospace Sciences Meeting sponsored by the American Institute of Aeronautics and Astronautics

Reno, Nevada, January 7-10, 1991 


\title{
A SUMMARY OF EXISTING AND PLANNED EXPERIMENT HARDWARE FOR
}

\author{
LOW-GRAVITY FLUIDS RESEARCH \\ Myron E. Hill and Terence F. O'Malley \\ National Aeronautics and Space Administration \\ Lewis Research Center \\ Cleveland, Ohio 44135
}

\begin{abstract}
SUMMARY
This paper provides (1) an overview of existing ground-based, low-gravity research facilities, with examples of hardware capabilities, and (2) an overview of existing and planned space-based research facilities, with examples of current and past flight hardware. Low-gravity, ground-based facilities, such as drop towers and aircraft, provide the experimenter with quick turnaround time, easy access to the equipment, gravity levels ranging from $10^{-2}$ to $10^{-6} \mathrm{~g}$, and low-gravity durations ranging from 2 to $30 \mathrm{sec}$. Three distinct low-gravity Lewis Research Center facilities (two drop towers and a Learjet) are described in addition to the 100-Meter Drop Tower at the Marshall Space Flight Center and the KC-135 aircraft stationed at the Johnson Space Center. The range of experiment capabilities and types is described for each facility. Currently, the only operational space-based facility is the space shuttle. The shuttle's payload bay facilities that are described include the Get-Away-Special canisters, the Materials Science Laboratory, and the Spacelab. The Spacelab facility offers the widest range of power distribution, thermal control, data management, and crew support. The shuttle's middeck facility, located beneath the main flight deck, is also described. Space-based facilities planned for the space station are in the conceptual definition phase; the concept of a modular, multiuser Fluid Physics/Dynamics Facility is presented. In summary, this document describes existing and planned low-gravity fluids research facilities with examples of experiments and hardware capabilities. Each of the facilities from the drop towers to the multiuser space station facilities - will play an important part in a successful low-gravity fluids research program.
\end{abstract}

\section{INTRODUCT ION}

Although low-gravity fluids research has been conducted since the early 1960 's, it is a scientific discipline that is still in its infancy. Not until permanent on-orbit fluids research facilities are available, notwithstanding the significant amount of research conducted in ground-based facilities, will the full potential of this discipline be realized. This paper briefly summarizes NASA's ground-based and space-based low-gravity facilities and presents an overview of selected experiments that have been developed for use in these facilities.

\footnotetext{
Copyright (C) 1990 by the American Institute of Aeronautics and Astronautics, Irc. No copyright is asserted in the

United States under Title 17, U.S. Code. The U.S. Government has a royalty-free license to exercise all rights under the copyright claimed herein for Governmental purposes. All other rights are reserved by the copyright owner.
} 
In general, a low-gravity environment enables a researcher to investigate effects that may be masked in experiments conducted in normal gravity. On Earth, gravity-induced phenomena, such as hydrostatic pressure, buoyant convection, sedimentation, and stratification, typically dominate phenomena caused by forces or mechanisms, such as surface tension forces, shear forces, interfacial contact angles, and diffusion. Studies of these latter phenomena are therefore inhibited. A low-gravity environment provides the researcher with a means to better understand particular fluid dynamics phenomena, which are then no longer dominated by other, gravity-induced phenomena. Additionally, larger geometries and longer experiment times are possible in space-based experiments with the low-gravity environment. As a result, visualization of the phenomena is enhanced and longer time-scale transients can be observed. Improved understanding leads to superior numerical and modeling techniques that make possible improvements in design methodologies for space-based (as well as lunar and Mars-based) systems. It is also expected that the knowledge gained from lowgravity experiments will improve our understanding of normal-gravity, Earthbased systems and processes as well.

The low-gravity fluids area is an extensive and multifaceted one, as clearly demonstrated in reference 1 and shown in figure 1 . In addition, it can be seen from the figure that this discipline can support either fundamental or applied research. Many of the fundamental research experiments can be conveniently categorized into five major topic areas: (1) isothermal capillary phenomena, (2) capillary phenomena with heat transfer, (3) thermal/solutal convection, (4) first- and second-order phase transitions, and (5) multiphase flow. Reference 2 describes work involving Lewis in these five areas. Applied research, however, typically directs experiments to areas that will support the design of the numerous space-based systems that rely on fluid processes. Examples of such space-based systems include power distribution, thermal control, life support, long-term cryogenic fluid storage, and fluid acquisition and transfer systems.

Numerous facilities are available for conducting low-gravity fluids research. They range from drop towers, which have a relatively short duration of low gravity ( 2 to $5 \mathrm{sec}$ ), to aircraft, which extend the duration of low gravity to 20 to $30 \mathrm{sec}$ by means of parabolic trajectories, to sounding rockets, giving on the order of 5 min of low-gravity time, to the Spacelab, which increases the low-gravity time to hours. The first part of this paper is devoted to discussing the various capabilities of ground-based, low-gravity facilities (with the exception of sounding rockets). Examples of typical hardware that have been built for these ground-based facilities are also discussed. The remainder of the paper covers space-based, low-gravity facilities with a concomitant description of selected flight experiments and their hardware. In addition, planned capabilities for conducting low-gravity, space-based fluids experiments in modular, multiuser fluid dynamics facilities on Spacelab and the space station are also discussed.

\section{EXISTING EXPERIMENT HARDWARE}

\section{Ground-Based, Low-Gravity Facilities and Hardware}

The primary ground-based or suborbital facilities that are used for lowgravity fluids research include a variety of drop towers and aircraft. These 
ground-based facilities are described in reference 3. Each facility has unique operational capabilities and limitations that not only determine its effectiveness in satisfying the researchers' requirements and the types of experiments conducted, but also dictate the experiment hardware designs. Therefore, before discussing the hardware used in these facilities we will briefly describe the salient features of each type of facility.

Drop towers. - Although a number of smaller drop towers are used at various laboratories, the three facilities that provide the longest low-gravity test time and the purest effective low-gravity environment are the two drop towers at the NASA Lewis Research Center and another at the NASA George C. Marshall Space Flight Center (MSFC). By allowing a test package to free fall, these facilities offer low-gravity environments ranging from 2.2 to $5.2 \mathrm{sec}$ and effective low-gravity levels as low as $10^{-6} \mathrm{~g}$.

The method employed to reduce air drag on the experiment and thus assure these low-level gravity environments in a large measure determines the operating characteristics of the facility. For example, the 2.2-Second Drop Tower at Lewis, shown in figure 2(a), uses a drag shield that surrounds the experiment package during a free-fall distance of $30 \mathrm{~m}$. Because the experiment package free falls within the drag shield, the only external force on the experiment is the air drag associated with the package accelerating relative to the drag shield during the $2.2 \mathrm{sec}$ of free fall. A typical test rig, shown in figure $2(\mathrm{~b})$, experiences gravity levels of about $10^{-5} \mathrm{~g}$. The constraint of using the drag shield restricts the size of the experiment package and limits the experiment weight to less than $150 \mathrm{~kg}$. However, there are also advantages to this mode of operation in that the experimenter has ready access to the experiment package immediately before and after the drop; the simple package construction keeps the experiment costs low and enablès easy modifications to the experiment design; and as many as 15 drops can be made in a normal workday. The ease of operations is perhaps best illustrated by the fact that over 10000 test drops have been conducted in the 2.2-Second Drop Tower.

The other method used to reduce air drag on the experiment is to evacuate the environment in which the package free falls. This is precisely the method employed in the Lewis Zero-Gravity Facility, shown in figure 3(a). In this facility no drag shield is required to reach gravity levels down to $10^{-5}$, since the pressure in the 6-m-diameter, 130-m-long drop chamber in which the package falls is reduced to $10^{-2}$ torr. The mode of operation in this facility results in a low-gravity test time of $5.2 \mathrm{sec}$ and enables the deployment of larger and more complex experiment packages. Typically experiments are carried on the 1-m-diameter, 3.4-m-high drop bus; experiments weighing up to $450 \mathrm{~kg}$ can be accommodated. A typical experiment is shown in figure $3(\mathrm{~b})$. The penalties incurred to achieve these enhanced capabilities include higher hardware costs; longer periods of limited or no access to the package before and after a drop; and greater facility complexity, which reduces normal operations to one drop per day.

The 100-Meter Drop Tower at MSFC provides a range of capabilities in terms of experiment size, weight, and complexity that is somewhere between those of the previously described facilities at Lewis. Although the 4.2 sec of low-gravity test time that this facility provides indeed lies between the available times in the Lewis facilities, the MSFC facility, shown in figure 4 , 
also provides a unique capability because of its mode of operation. In addition to employing a drag shield, the MSFC drop tower also uses a set of guide rails rather than relying on pure free fall. In order to overcome the decelerating forces due to guide rail friction, the drag shield is given a downward thrust by a gas thruster system. This unique mode of operation also provides the capability for variable-gravity-level test conditions. By adjusting the thrust level, a controlled gravity level on the test package of $4 \times 10^{-2}$ to $1 \times 10^{-5} \mathrm{~g}$ can be provided. As many as 10 drops can be performed in one day at this MSFC facility.

In addition to the capabilities and limitations previously discussed, two other factors determine the effectiveness of any drop tower in meeting the needs of low-gravity fluids researchers. These factors involve events occurring at the beginning and end of any drop. At the beginning of a drop, when the experiment is released to free fall, the step change from normal gravity to low gravity can produce large transient effects in a fluid system. Although of ten overlooked when planning experiments, these transient effects and the length of time that they persist can significantly decrease the effective time available for observing low-gravity fluid processes or phenomena of interest. Conversely, at the end of a drop, there is a large change in effective gravity level as the package is decelerated and brought to rest. Peak deceleration levels as high as $70 \mathrm{~g}$ 's can be imposed on the experiment, and even though these peak loadings are of very short duration (i.e., on the order of milliseconds), they must be considered in the hardware design.

Drop tower experiment hardware. - In general, when compared with spaceflight hardware, drop tower experiment hardware, or rigs as they are commonly called, must be considered very flexible and amendable to design and hardware modifications. It is common practice to reconfigure or upgrade drop tower rigs as expanded capabilities are required, and in some cases the same basic rig is used in several research studies. Therefore, to keep our review of the fluids experiment hardware currently operational in drop towers brief, we will emphasize hardware capabilities rather than attempt to describe all available rigs. The discussion is structured in terms of increasing hardware capability and complexity. Detailed descriptions are often contained in the references.

The least complex drop tower rig is also one of the most common and is used to study processes under isothermal conditions with no externally imposed flow. Typically the core of an experiment is a transparent test container partially filled with a single liquid or various combinations of immiscible liquids. The variable experiment parameters include the container geometry, container surface properties, liquid properties, and liquid fill levels. The general fluid motion and liquid/gas or liquid/liquid interface behavior is usually recorded by using motion picture film or video systems. References 4 and 5 discuss experiments of this type. New capabilities have recently been added to several rigs by using a laser light source to provide light sheet illumination of the fluids. This enables the tracking of particles in a plane of the fluid volume and hence a much more accurate interpretation of the fluid flows. 0ther versions of these rigs have added the capability to provide external forcing functions on the container; various modes of liquid sloshing can be induced by controlling the amplitude and frequency profile of the driving force. 
The next level of design complexity and enhanced experiment capabilities generally involves the addition of heat flux or externally driven flows. A heat flux can be added and controlled in a number of ways. One drop tower experiment has used a radiant heat source in an at tempt to initiate thermocapillary flow on the liquid/vapor interface (ref. 6). Obvious variables include heat flux, heater geometry, distance of the heater from the liquid surface, and container geometry. In addition to a video recording of the gas- and liquidphase fluid flows, other measured parameters include temperatures at various locations in the gas and the liquid. Heat flux has also been applied directly to a bulk liquid through a variety of ways in a number of past boiling studies (refs. 7 to 9). In a recent drop tower experiment to investigate low-gravity pool boiling, heat was supplied by a flat-plate heater to a liquid fluorocarbon (Freon 113) whose saturation temperature and initial subcooling conditions were precisely controlled. The primary experiment variables included heat flux and initial bulk liquid temperature. By employing a thin, semitransparent film of gold deposited on quartz as the heater surface, the processes of bubble nucleation, growth, and departure could be observed both from beneath and parallel to the heater. In addition to the photographic record of the bubble dynamics, other data acquired include bulk liquid temperature distribution, test chamber pressure, and heater temperature.

Like imposed heat flux, forced flow can be incorporated in a drop tower fluids experiment in a number of ways. The flow can be either of a single phase or multiphase fluid. Past experiments of the single-phase type have studied both gas and liquid flows under a large variety of system conditions and test geometries. Both mechanically pumped and pressurized-source liquid flows have been used to study such phenomena as liquid jet stability characteristics, jet interactions with solid and liquid surfaces, and bulk liquid motion in response to incoming liquid flows (refs. 10 to 12). Pressure-driven gas flow studies have generally focused on investigations of the interaction of gas jets with liquid surfaces (refs. 13 and 14). Most of the acquired data has been in the form of motion picture or video recordings with accompanying measurements of inlet flow velocities.

Most multiphase flow studies have concentrated on the simultaneous forced flow of liquid and gas through simple conduit geometries, such as those with circular cross sections (refs. 15 and 16). Primary control parameters have been the superficial gas and liquid flow rates or velocities, and most of the acquired data has consisted of photographing the flow pattern with some accompanying pressure drop measurements. Recent additions to drop tower experiment hardware have provided a capability to investigate the effects of varying conduit geometries, such as fittings or bends, and the effects of different inlet mixer configurations.

In addition to the rather general-purpose experiment hardware just described, a number of unique drop tower rigs have also been developed to address highly specialized research and technology development study requirements. For example, rigs have been successfully implemented to study additional fundamental fluid processes or phenomena, such as mass transport or bubble migration and dynamics, as well as to evaluate in-space fluid management techniques or technologies, such as screened liquid acquisition devices and liquid/vapor separators. The experiments described are not a complete 
list of the experiments that have been conducted, but they demonstrate the range of possible studies that can be conducted in drop towers.

Aircraft. - Specially modified jet aircraft flying parabolic trajectories can provide longer low-gravity experiment times than drop towers, but they cannot attain the low-gravity levels of the drop towers. For an experiment fixed to the body of an aircraft, effective gravity levels on the order of $10^{-2} \mathrm{~g}$ can be attained for about 20 to $30 \mathrm{sec}$. Several trajectories are possible during one flight. Although aircraft do not offer true microgravity, they do offer the significant advantages of permitting researchers not only longer durations at low gravity, but also real-time monitoring of experiments, and the chance to reconfigure the experiment between trajectories.

The Lewis airborne low-gravity facility, a Learjet model 25, is shown in figure 5 along with a flight profile of a low-gravity trajectory. Approximately $1.8 \mathrm{~m}$ of cabin length is available for experiment mounting and researcher seating. The inherent engine lubrication limitations of this aircraft permit a maximum of six trajectories per flight. Intermediate acceleration levels varying from $1 / 20$ to $3 / 4$ of Earth's gravity, including lunar $(1 / 6 \mathrm{~g})$ and Martian (1/3 g), can also be achieved in this aircraft.

The Johnson Space Center's KC-135 aircraft operates like the Learjet when flying experiments fixed to the aircraft body, but because of its size also permits free-floating experiments with acceleration levels of about $10^{-3} \mathrm{~g}$ for 5 to $15 \mathrm{sec}$. As many as 40 parabolic trajectories are performed per flight with experiments in a research bay that is $3 \mathrm{~m}$ wide by $16 \mathrm{~m}$ long. This aircraft, like the Learjet, can perform variable-gravity-level acceleration parabolas.

Sounding rockets can provide a low-gravity environment on the order of $10^{-4} \mathrm{~g}$ for about $300 \mathrm{sec}$. Their use should be considered in experiments that require such a duration and gravity level but do not require direct observation by a researcher.

Aircraft experiment hardware. - Aircraft hardware more of ten than not tends to be an extension or enhancement of the already described drop tower hardware. The ideal types of experiments suitable for the aircraft facilities are those (1) that do not need extremely low levels of gravity (i.e., those for which $10^{-2} \mathrm{~g}$ is adequate), (2) that can significantly benefit from the longer low-gravity times available (on the order of $20 \mathrm{sec}$ ), and (3) that can significantly benefit from being larger. For these reasons, the emphasis in recent years has been directed to conducting two-phase-flow experiments on aircraft facilities. The phenomena studied are not as sensitive to the relatively higher gravity levels attained in the aircraft (compared with the drop towers), and the experiments are physically larger than other types of fluids experiments because they require forced flow.

Generally, two types of multiphase flow experiments have been conducted in low gravity. In the least complex isothermal case, with no heat transfer, the areas of primary importance are flow patterns, phase distributions, and pressure drop characteristics. These phenomena are influenced by buoyancy and pressure head in a normal-gravity environment. Isothermal two-phase flow experiments have been typically conducted with an air-water type of system, in which both fluids are introduced separately into a mixer before entering the 
test section. Gas superficial velocities on the order of $10 \mathrm{~m} / \mathrm{sec}$ and liquid superficial velocities on the order of $1 \mathrm{~m} / \mathrm{sec}$ have been obtained. Important experiment parameters that are typically varied include the relative fluid velocities and such fluid properties as viscosity and surface tension. An example of research being conducted in this isothermal area in discussed in reference 16 .

The next step up in complexity introduces heat transfer into the multiphase loop. In this case the phenomena of interest include not only those listed for the isothermal case (e.g., flow patterns), but also the nature of the heat transfer itself. There is, in this case, an intimate coupling between heat transfer and momentum effects, as manifested in the heat transfer coefficients. Studies such as these have been conducted on aircraft with circulating flow loops in which flow boiling and condensation are occurring. Examples of such experiments are discussed in references 17 and 18.

\section{Space-Based Hardware}

The previous section described low-gravity, ground-based facilities (both drop towers and aircraft), their capabilities, and representative experiments for each. The longest low-gravity time achievable in these facilities is about $25 \mathrm{sec}$ (at $10^{-2} \mathrm{~g}$ or less) in the KC-135 aircraft. The next step up in providing longer low-gravity times is to go to an on-orbit situation. (Sounding rockets, which typically bridge the gap between aircraft and on-orbit facilities, are presently not widely used by investigators in the United States and therefore are not discussed in this paper.) Currently, the primary on-orbit facility in which U.S. fluids researchers can conduct experiments in low gravity is the space shuttle. Although some U.S. investigators may have opportunities to conduct experiments on foreign space platforms, such as the Soviet Mir facility, these opportunities are very limited and therefore are not discussed in this paper.

There are definite advantages to performing on-orbit, low-gravity experiments that can counterbalance their relatively higher cost and longer turnaround times. The primary advantage, of course, is the almost unlimited time available to the experimenter at very low gravity levels. This, in turn, allows a more diverse matrix of study objectives and more sophisticated experiments. Diversity also describes the types of facilities the shuttle offers experimenters. They range from small volumes with no direct orbiter support to larger experiments that may require a broader range of data, power, thermal, and crew support. The various facilities available on the shuttle are briefly described here.

There are primarily two locations for shuttle facilities: the payload bay and the middeck area. Figure 6 shows the payload bay; the middeck is located in the crew area near the forward part of the ship. Payload bay experiments can be located in either pressurized or unpressurized areas. The most common pressurized environment available in the payload bay is that provided by the Spacelab module. A full range of orbiter support (data, power, and thermal) is provided here and at the Spacelab pallet (with the exception of direct crew interaction). The pallet is located in the unpressurized cargo bay, and experiments located there of ten require exposure to space and its vacuum. A second 
facility located in the unpressurized cargo bay is the Materials Science Laboratory (MSL). The capabilities of the MSL (in terms of power and data) are not quite as comprehensive as those of the Spacelab but are better than those of the middeck area (to be discussed). The last component rounding out the unpressurized payload bay facilities are the Get-Away-Special canisters, commonly known as "GAS cans." These are relatively small self-contained experiments conducted with no orbiter support. The advantages of choosing the GAS can capability include lower cost, more frequent flight opportunities, and quicker access to data.

The final shuttle facility to be discussed is the middeck. It is located beneath the main flight deck and includes fore and aft sections. Because the middeck's primary purpose is crew storage, it consists of 42 storage lockers. On a mission-by-mission basis a number of these lockers may become available for low-gravity experimentation. Different ways of accommodating experimenters here is discussed in more detail later. Some orbiter power and thermal cooling is provided through middeck facilities.

The following paragraphs present the detailed capabilities and limitations of each shuttle option. Selected flight experiments are described for each facility. The number of experiments selected for discussion is by no means complete and is intended to present only representative examples.

Payload bay/GAS can facility. - The Get-Away-Special (GAS) facility, the smallest and most versatile of all the shuttle microgravity facilities, is shown in figure 7 . The GAS canisters (or cans) provide users with an economic method of conducting experiments on the orbiter. Other advantages of GAS cans include more frequent reflight opportunities and easier access to the experiment before launch and after landing. These self-contained units (large version) are $50 \mathrm{~cm}$ in diameter and $72 \mathrm{~cm}$ high and have a 91-kg payload capacity. The GAS cans can be placed in various locations within the payload bay and may even be used to fine-tune the orbiter's center of gravity. The shuttle provides no power, data management, or thermal control services to GAS can users other than on/off controls operated by the crew. Power and data management must be user supplied, and all related experiment equipment must be contained within the GAS can. Thermal control is usually passive.

Various examples of fluid physics experiments that uses this facility are given here. It must be emphasized, as mentioned previously, that not all GAS can fluid physics experiments can be discussed here, only representative examples. The hardware for these experiments has been developed by a large variety of organizations, and the examples given are divided among those built by industry, academia, and the Government. One example is given for each.

Tank Pressure Control Experiment: The first experiment to be discussed is shown in figure 8 and is discussed in reference 19. This experiment, the Tank Pressure Control Experiment, is being built by Boeing Aerospace as the prime contractor with Washington University as a subcontractor. It is a technology-based experiment having application to space-based storage of cryogenic liquids. Such technology is needed, for example, for orbital transfer vehicles and the supporting propellant storage vessels. Practically no lowgravity thermodynamic data are available on liquid/vapor systems. The primary objectives of this experiment are to study how jet-induced mixing destratifies the fluid (bringing it closer to equilibrium) and to record the corresponding 
system pressure decay response. Other objectives are threefold: (1) to characterize the fluid dynamics of mixing, (2) to use low-gravity data to evaluate the applicability of normal-gravity mixing models, and (3) to improve existing computer codes.

The experiment, to be flown in June 1991, will use Freon 113 as the test fluid (at a 85-percent fill level) and use a container that simulates a typical tank used for propellant storage. The tank volume is 9 liters and pressures are expected to range between 2 and 15 psia. About 40 runs are contemplated at various heater/flow rate (up to $1 \mathrm{gal} / \mathrm{min}$ ) combinations, and pressure, temperature, and visual data will be taken as the tank contents are alternately heated and mixed (10 min of heating, $15 \mathrm{~min}$ of mixing, and $15 \mathrm{~min}$ of quiescence). The various hardware components are shown in figure 9. The data will be used to improve mixing correlations and to validate computer codes that in turn will be the design tools for future space-based cryogenic tankage.

Thermocapillary Flow Experiment: The second GAS experiment to be discussed, which was developed by Utah State University, is entitled "Thermocapillary Flow and Gas Convection in Micro-g" and was flown on shuttle mission 41-G. Thermocapillary flow was studied in a differentially heated cylinder containing paraffin. This experiment, discussed in reference 20, has material processing applications in that a float-zone configuration was modeled. Such thermocapillary flow, shown in figure 10 , is expected to be laminar for small Marangoni numbers and to transition to transient oscillatory flow at Marangoni numbers of about 10000 .

The paraffin cylinder was held between two rods and was $1.5 \mathrm{~cm}$ long and $0.63 \mathrm{~cm}$ in diameter. The two rods were held at different temperatures, thus differentially heating the sample. Figure 11 shows the rod hardware. After one-half hour of warmup, two runs were conducted, separated by an hour of cooldown. Early in the runs, when Marangoni numbers were lower, steady laminar thermocapillary flow was established. At Marangoni numbers above 10000 , transition to oscillatory flow was expected to begin. This periodic flow was established at a Marangoni number of about 30000 with a period of about 8 sec. Suspended tracer particles in the paraffin were used to facilitate flow visualization. (It was fortunate that two runs were made as a camera failure precluded getting any visual data on the first run.) Interestingly, several observations were unexpected. First, a large amount of natural convection in the gas phase was observed in the form of a vortex. Second, at the higher Marangoni numbers cellular behavior was uneven. There was some discussion as to how much of a role microgravity convection, g-jitter, and thermal expansion convection played in the unexpected behavior. It was postulated that interaction between the gas and the liquid was a key factor in the transient oscillatory flow.

Capillary Pumped Loop Experiment: The third and final GAS experiment to be discussed is the Capillary Pumped Loop (CPL) Experiment developed by Goddard Space Flight Center (GSFC) (ref. 21). The CPL flew twice in 1985 in the GAS configuration - in April on shuttle mission 51-D and in June on 51-G. The CPL system, shown in figure 12 , is a candidate design for future spacecraft thermal control systems. The capillary pumped-loop approach acquires and transports heat nearly isothermally for long transport distances and under a wide range of power levels. Although a mechanical pump assist may be available on future systems, the evaporators use porous wicks and the system itself has no 
moving parts. The objective of these tests was to verify low-gravity system performance.

Ammonia was the working fluid, mirroring the fact that it is the fluid of choice on contemplated Space Station Freedom thermal control systems. The capillary pumps, the condenser section, and the fluid reservoir (which provided fluid inventory control as well as loop setpoint temperature control) were the major fluid components. The largest volume of space inside the GAS can, however, was occupied by batteries and assorted electronic hardware. The actual flow loop was enclosed in a $35-$ by $35-$ by $10-\mathrm{cm}$ volume that was attached to the GAS can top plate as shown in figure 13. The battery, the tape recorder, and the support structure used were from flight-proven designs, thereby saving on cost. Only $220 \mathrm{~W}$ of power were required. A full-scale CPL experiment with a $40-\mathrm{ft}^{2}$ radiator is planned for 1992 .

The system operated very well for the entire 120-hr 51-G mission during which 13 power cycles were performed. Little difference was found between normal-gravity and microgravity system performance.

Payload bay/Material Science Laboratory (MSL) facility. - The MSL facility, shown in figure 14 , is the next higher level of capability available in the unpressurized payload bay. It can accommodate heavier payloads and provides users with power, data, and environmental and thermal control capabilities. The MSL can have as many as three experiments simultaneously mounted on its triangular-shaped truss structure, called the MPESS (multiuser payload experiment support structure). Experiment weights are limited to $308 \mathrm{~kg}$ (assuming three experiments are flown), and areas on the top and bottom of the MPESS are limited to approximately 80 by $100 \mathrm{~cm}$. An MSL experiment apparatus container (EAC) $42 \mathrm{~cm}$ in diameter and $99 \mathrm{~cm}$ high is made available to users for containment purposes. Power levels of $470 \mathrm{~W}$ (assuming three experiments are flown) can be continuously provided.

Each experiment can either be controlled by crew personnel, operated from the ground, or completely automated. Although some orbiter integration is required (therefore increasing turnaround time), it is less than that required for Spacelab experiments. Materials experiments with a fluid emphasis as well as basic fluid physics experiments have been conducted on or are planned for the MSL. Selected examples of planned experiments are described here.

Isothermal Dendritic Growth Experiment (IDGE): The IDGE apparatus will allow investigators to study dendritic crystal growth physics with organic materials that simulate pure metals and metal alloy systems. See reference 22 for a detailed description of the experiment. The IDGE experiment, shown in figure 15, will be an MSL experiment and is scheduled for launch in 1992 . Dendritic growth of a "metallic" solute undergoing solidification is one of the more common types of morphology and is manifested by the growth of pine-tree-like branches as the freezing progresses. The kinetics of this dendritic growth, which ultimately affects the material properties, can be significantly influenced by whether or not natural convection is present in the solute. In fact, current theory can only predict the experimental results (in terms of dendrite tip velocity and radius) for the larger subcooling levels where heat transfer mechanisms dominate fluid motion. In low gravity, fluid convection will be greatly reduced, thereby allowing more appropriate comparison of theoretical and experimental results obtained at these lower 
subcooling levels. A side benefit of this is that lower tip velocities and larger radii will enhance data-gathering abilities.

The key elements of the IDGE apparatus are a sealed, temperaturecontrolled bath, a photographic data collection system, and a crystal growth chamber. See figure 16 for test module detail. The bath, which contains high-power and low-power heater coils, consists of a mixture of ethylene glycol and water that has the same refractive index as the test fluid, succinonitrile (SCN). The larger coil is used mainly for initial warmup (up to $59{ }^{\circ} \mathrm{C}$ ) and remelting of the solid SCN. Once the proper conditions are reached, four thermoelectric coolers near the stinger (injector) are turned on, thereby driving local fluid temperatures down to the desired subcooled values. Nucleation of the SCN proceeds down the stinger to the vicinity of the crystal growth chamber, where the phenomenon is photographed. Two 35-mm still cameras, with focal lengths of $80 \mathrm{~mm}$, are the main data-gathering components. Current plans call for 10 subcoolings in the range 0.1 to $1.0{ }^{\circ} \mathrm{C}$ each to be run twice for a total of 20 runs.

Critical Fluid Light Scattering Experiment (CFLSE): This shut le MSL experiment, shown in figure 17 , will study certain fluid property anomalies that occur near a fluid's critical point. One of these anomalies is that the fluid becomes infinitely compressible at its critical point. Measurements that will be taken, as temperatures approach the critical value, include the correlation lengths (derived from the sample scattering intensities and sample turbidity measurements) and the density fluctuation relaxation times. The CFLSE's will approach to within 100 microkelvins of the fluid's critical value. In a normal-gravity environment the existence of a relatively large pressure head relegates the critical region to a thin band of fluid, thereby making accurate critical-point measurements difficult. The long-term, low-gravity environment widens this band and makes possible accurate decay rate and correlation length measurements. Optical transmission and dynamic laser light scattering methods will be used to make these measurements. More detailed discussion can be found in reference 23 .

The sample fluid is high-pressure xenon (58 atm) at ambient temperature $\left(17{ }^{\circ} \mathrm{C}\right)$ and occupies only $2 \mathrm{ml}$. CFLSE's require precise optical alignment, temperature control $( \pm 0.001 \mathrm{deg} C)$, and vibration isolation (less than $\pm 0.001 \mathrm{~g})$. Density fluctuation data will begin to be taken when the fluid temperature is within 1 kelvin and will continue until the temperature is within 100 microkelvins of its critical value. See figure 18 for test module details.

Payload bay/Spacelab facility. - The Spacelab facility has two major components: the pallet and the module. The unpressurized pallet offers experimenters direct access to space or vacuum while maintaining full orbiter support capabilities. The module (which has a short and a long version) is the pressurized compartment within the cargo bay and has the added feature of hands-on crew interaction capability. These major components are shown in figure 19. The total Spacelab power level provided is $7 \mathrm{~kW}$. In the Spacelab module the crew can actively participate in the users' experiments. Experiments are housed in either single or double racks; the single-rack volume is $0.9 \mathrm{~m}^{3}$. The pallet and the module offer the same electrical and data capabilities. The pallet thermal cooling is tied to the orbiter's main fluid loop; the module racks are conditioned by circulating air either with or without a water heat 
exchanger. The Spacelab complex can be configured into three basic modes: (1) all unpressurized pallets (five maximum), (2) mixed mode, module plus pallets (two maximum), and (3) module only. The basic advantages of Spacelab are the flexibility it affords experimenters and the larger size and higher power levels that the experiment can attain. Disadvantages include increased cost and longer turnaround time. Some of the experiments that have been designed for the Spacelab are discussed here.

Drop Physics Module (DPM): The aim of the DPM, as with its Spacelab 3 predecessor the Drop Dynamics Module (DDM), is to study the motion, dynamics, and shape of drops subjected to a variety of acoustical forces. The dynamics of free drops is discussed in reference 24 . These forces can promote droplet rotational, positional, and shape-wise oscillations. In the past, acoustical positioning and perturbation techniques have been used in ground-based, lowgravity facilities; however, the level of detail and quantity of data acquired were insufficient to verify the theory. It is expected that the DPM will yield data revealing the thermocapillary and thermal inertia interactions unmarred by gravitational effects.

The DPM, shown in figure 20, is a multipurpose, acoustic positioning device that will occupy a Spacelab double rack. It has two independent chambers that accommodate near-ambient-temperature and high-temperature samples. The near-ambient chamber will operate at $100{ }^{\circ} \mathrm{C}$ and accommodate drops up to $2.7 \mathrm{~cm}$ in diameter; the high-temperature chamber will operate at approximately $1000{ }^{\circ} \mathrm{C}$ and accommodate droplets up to $1 \mathrm{~cm}$ in diameter. The investigator will be able to control the module's humidity, lighting, pressure, temperature, and acoustic driving force and the host gas composition.

Fluid Experiment System (FES): The FES is a multipurpose system that allows low-gravity studies of transparent fluids in the areas of convection, surface-tension-controlled phenomena, fluid immiscibility, and phase change. Figures 21(a) and (b) show the facility schematic and the test cell detail, respectively. The FES is a Spacelab facility with downlink, ground monitoring capability. One class of experiments that can be performed in this facility is crystal growth tests. The one to be highlighted here, however, is one that has application in the solidification of metals, the Casting and Solidification Technology (CAST) Experiment.

CAST is scheduled for flight on shuttle mission IML-1 in December 1991, in which solidification front morphology and solutal fluid motion will be studied. The growth front morphology is a function of temperature gradient, front velocity, composition, and fluid motion. Three phenomena in particular are to be studied: constitutional supercooling, freckling, and dendrite coarsening. Because gravity is expected to influence both the fluid flow and nucleation phenomena, low-gravity experiments will be able to answer whether supercooling or fluid motion causes the formation of crystallites, to what degree freckling may be caused by liquid plumes emanating from the dendritic front, or to what degree dendrite coarsening may be affected by convective fluid motion.

The CAST experiment will use an ammonium chloride and water mixture to simulate metallic alloy solidification. Figures $22(a)$ and (b), respectively, show the optical path (with the cuvette integrated into the FES) and details of the cuvette itself. The cuvette holding the fluid mixture (28 percent $\mathrm{NH}_{4} \mathrm{Cl}$ ) 
measures 29 by 20 by $12 \mathrm{~mm}$. Two opposite sides are for viewing and another pair of opposite sides is used for temperature gradient application. There are three flight samples; two will undergo a total of 11 tests and the other will be used for calibration. Three gradients are planned for each run in the range 5 to $28 \mathrm{deg} \mathrm{C} / \mathrm{cm}$ with each run lasting 0.5 to $2 \mathrm{hr}$. More details on CAST can be found in reference 25 .

Surface-Tension-Driven Convection Experiment (STDCE): The STDCE, summarized in reference 26 , is planned to fly on shuttle mission USML-1, currently scheduled for May or June 1992. This experiment will study fluid flow phenomena that result when temperature gradients are imposed upon a liquid/gas interface. These temperature gradients (parallel to the fluid interface) create surface tension imbalances on the surface that result in the flow of fluid from areas of relatively high surface tension to areas of relatively low surface tension. An understanding of such thermocapillary flow is important in many planned space-based processes (e.g., containerless processing). Not only are steady-state flows of interest, but transient, oscillatory fluid motion is of particular interest. These oscillatory flows have been observed in microgravity environments, but better quantified data need to be obtained. The main data of interest are surface temperature distributions and two-dimensional flow field data.

The STDCE experiment apparatus is to be contained in the left side of a Spacelab double rack. The right side mainly contains a television monitor and an avionics package. Refer to figure 23 (showing only the left side of the double rack) for details. The actual fluid cell will contain 10-centistoke silicone oil in a container that is $10 \mathrm{~cm}$ in diameter and $5 \mathrm{~cm}$ high. The surface tension flows will be generated in two separate modes of operation. The constant flux (CF) mode directly heats the surface of the Iiquid with a $\mathrm{CO}_{2}$ laser. This laser is selected so that liquid surface heating occurs in a very thin surface layer (on the order of $1 \mathrm{~mm}$ ). The other heating mode of operation, the constant temperature (CT) mode, uses a constant-temperature heated surface (the immersed heater is removed in the CF experiments) and a cooled outer containing wall. These temperature-controlled surfaces provide welldefined conditions that drive the subsequent thermocapillary flow. Experiment runs will be made to study not only various levels of heat flux (CF) and surface temperature (CT) conditions, but various liquid levels (and therefore different surface curvatures) as well. The surface temperature distributions are gathered by an infrared imager. The flow field data are obtained by using laser light sheet and particle seeding techniques. A diode laser optical system is used to produce the laser light sheet, and aluminum oxide particles (about $50 \mu \mathrm{m}$ in diameter) are used to seed the fluid.

Orbiter middeck. - The middeck facility combines some of the advantages of the lower cost GAS can experiments with the crew interaction capability of the Spacelab module. The middeck, as shown in figure 24 , comprises the fore and aft sections below the main flight deck of the orbiter. Although this area's primary purpose is to provide stowage space for the crew's needs, on some flights a number of these storage lockers are not required for crew needs and they are then available to support microgravity experiments. Single or double lockers exist; the single locker dimensions are 56 by 53 by $201 \mathrm{~cm}$ $(\mathrm{L} \times \mathrm{W} \times \mathrm{H})$. Also available to middeck users are experiment apparatus containers (EAC's) similar to the payload bay EAC's. Even though there are three versions 
of the middeck EAC's as pictured in figure 25, the cylindrical versions are removable, and all versions provide the necessary containment capabilities.

When more volume is required, the user can use the middeck accommodations rack (MAR) structure to house the experiment. The MAR, when used, is located where the galley is indicated in figure 24 and has been designed to permit the integration of small payloads in the middeck. Some power distribution and thermal control capability is provided with the MAR. In all cases with middeck facilities the user provides all data and instrumentation functions; the orbiter provides limited power and thermal capabilities and can accommodate payloads as heavy as $157 \mathrm{~kg}$. There is generally only limited active thermal cooling provided for experiments in the storage lockers. As with GAS can experiments the middeck offers users relatively more frequent flight opportunities. It is, however, more prone to crew disturbances and subject to stricter safety requirements as the middeck area is considered a safe haven for the crew. Some of the experiments that have used the middeck facilities are discussed here.

Fluid Experiment Apparatus (FEA): The FEA, as shown in figure 26, is an apparatus developed by Rockwell International that can provide investigators with the ability to study basic space processing in a variety of disciplines including chemistry, crystal growth, fluid mechanics, thermodynamics, and biology. It is designed to be a modular, low-cost apparatus whose first version (FEA-1) is designed for float-zone crystal growth applications. The experiment to be described is such a float-zone study.

A float zone is a volume of liquid suspended between two discrete volumes of solid-phase material. The flows that are generated in this zone can be due to accelerations, volume change upon solidification or melting, and thermocapillary effects. The last is the focus of the discussion here. It is believed that for high enough Marangoni numbers (on the order of $10^{4}$ ) oscillatory flow will be established in the melt, thereby causing impurity striations upon resolidification. From a materials standpoint these striations are undesirable. For lower Marangoni numbers, steady thermocapillary flow will occur, yielding a more uniform, homogeneous distribution of impurities.

One in-space experiment conducted in the middeck FEA was launched in September 1984. The results are summarized in reference 27. The material melted was indium, which melts at $429 \mathrm{~K}$ and has a very low vapor pressure, a low Prandtl number (0.013), and a relatively high surface tension (558 dynes/cm). The FEA can accommodate a sample $1 \mathrm{~cm}$ in diameter and $21.6 \mathrm{~cm}$ long. The actual experiment began with a polycrystalline portion $16.2 \mathrm{~cm}$ long doped with $100 \mathrm{ppm}$ of thallium that was joined to a single-crystal seed portion $5.4 \mathrm{~cm}$ long. The melted zone was between the polycrystalline and seed portions of the crystal. Marangoni numbers on the order of 100 were achieved, implying that only steady, laminar thermocapillary flow was realized.

Martin Marietta Storable Fluid Management Demonstration (SFMD): The SFMD was the first experiment that demonstrated the feasibility of propellant tank refill in low gravity for extended periods of time. The objectives of the experiment were to demonstrate the filling of a receiver tank that contained a liquid acquisition device (LAD) and also to demonstrate, in low gravity, the 
expulsion of propellant from the receiver to a supply tank (see ref. 28). Such technology would help support on-orbit resupply in the future.

The SFMD was an orbiter middeck experiment (launched in July 1985) that used the equivalent of four storage lockers and consisted mainly of a receiver and a supply tank (both $31.7 \mathrm{~cm}$ i.d.); see figure 27. The receiver tank had the LAD to control the liquid/vapor interface during filling and draining; the supply tank had an elastomeric bladder that was used to control the fill/drain rate. Air was used to pressurize the bladder, and the tanks were maintained at about 20-psig pressure. Sixteen hours of testing were completed, which included nine separate tests. Each test consisted of a receiver tank refill followed by a receiver tank expulsion. Receiver tank venting prior to filling removed noncondensibles and allowed a more complete filling. The objective of the receiver tank liquid expulsion tests was to measure the expulsion efficiency; namely, how much liquid remained in the tank upon vapor injection. No vapor was ingested, in any case, until residuals were fairly small. The predicted expulsion efficiencies were 92 percent; efficiencies as high as 94 percent were measured. It is expected that for larger tanks and slower $\mathrm{fill} / \mathrm{drain}$ rates, the efficiencies could be as high as 98 percent.

Diffusion Mixing of Organic Solutions (DMOS) Experiment: It has been postulated that space-grown crystals could be larger and of better quality than those grown on Earth. In normal gravity, buoyancy (leading to solutal convection) and sedimentation must be dealt with in the crystal growing process. In microgravity these processes are expected to be insignificant relative to the diffusion mass transport process. In the first set of DMOS experiments, higher than expected g-levels were realized, thereby causing significant solutal convection. Therefore, DMOS-2, flown on flight 61-B, was conceived to characterize the transport mechanisms, whether diffusive or convective, under existing g-levels and to examine their effect on crystal growth. See reference 29 for details.

This aft middeck apparatus contained six three-chambered cells (each cell being $250 \mathrm{ml}$ in total volume and $20 \mathrm{~cm}$ high and weighing $22 \mathrm{~kg}$ ). A cell schematic is shown in figure 28 . The package weighed $430 \mathrm{~kg}$ and occupied three storage lockers. After the gate valves were opened, component mixing occurred and the valves remained open for a period of $130 \mathrm{hr}$.

Two of the six cells were fluid mixing cells; the others were crystal growth cells. In one fluid cell, mixing of fluids closely matched in density was studied; the other cell had constituents whose densities differed by a factor of 2. The mixing cells showed signs that were attributed to extensive convection. This conclusion was reached (1) because the measured component mass percentages in the respective cells indicated nearly equilibrium status and (2) because calculations indicated that $2000 \mathrm{hr}$ was necessary for a diffusioncontrolled equilibrium state to be reached. In the other fluid mixing cell (with the small density difference), the components remained largely unmixed after $130 \mathrm{hr}$ and, in fact, the measured component concentrations agreed well with predictions for diffusion-controlled mixing. These results were expected to bracket the results in the crystal growth cells. Since in earlier European Spacelab flights crystals of significantly better quality than those grown in normal gravity were grown in space, it was expected that such would be the case 
here. However the crystals in DMOS-2 were essentially of the same quality as those grown on the ground.

\section{PLANNED EXPERIMENT HARDWARE}

The in-space experiment facilities described thus far (i.e., those carried on the space shuttle) have been designed primarily to focus on rather unique experiments. Experiment hardware of the future will consist not only of similar upgraded shuttle-based hardware, but also of modular, multiuser facilities designed for Space Station Freedom as well as the shuttle. Present planning indicates a bright future for the low-gravity fluid physics program. Current plans not only include upgrades to existing hardware, such as to the Surface Tension Driven Convection Experiment (STDCE) for example, but also new hardware, such as the Advanced Fluids Module (planned for Spacelab) and the Fluid Physics/Dynamics Facility (planned for Space Station Freedom). One of the major differences between the present hardware and planned hardware is the modular, multiuser capabilities that will be inherent in the design of new experiment hardware. This concept is shown in figure 29. These facilities are described following a discussion on the modular approach.

\section{Modular Approach}

The modular, multiuser philosophy has evolved, in part, because of the high cost of building flight hardware. It is anticipated that it will be less expensive to modify or reuse existing hardware than it would be to build new hardware. If new hardware is designed with reuse in mind, changing hardware would be a less complex procedure. Also, it is anticipated that fluid physics experiments would be able to use the common designs of such subsystems as imaging, thermal control, and data systems, which would conceivably remain the same from one experiment to the next. Experiment-specific hardware such as optics, test cells, and fill systems could be designed to be modular and therefore easily modified. One important characteristic of a modular component or system is a simple, well-defined interface with the rest of the hardware. The design of modular, multiuser hardware will be challenging, as varied and possibly conflicting requirements will be placed on the hardware.

\section{Hardware Modifications}

Future experiments whose development can be achieved in the shortest time using the least resources are those that will result from modifications to existing hardware. Upgrades to existing experiments, such as STDCE, are planned. The STDCE upgrade could include, for example, modifying the flow visualization system and enhancing the capability for on-orbit changeout of the test chamber and test fluids. In general, these upgrades will enhance the scientific return for the particular class of experiment, but most likely will not allow other fluid phenomena to be investigated. 


\section{New Hardware}

Advanced Fluids Module (AFM). - The AFM, as envisioned, will be able to accommodate a variety of investigators and experiments. The AFM, in the very early design stages, is planned to fly on Spacelab in 1997, with the possibility of also being flown on Space Station Freedom in its early man-tended configuration. The module would probably have a double-rack configuration (two 19-in. racks) with some of the following hardware characteristics: on-orbit test cell and test fluid changeout, common diagnostic techniques, fluid containment and cleanup capability, and thermal conditioning equipment. The test cells would typically be on the order of 10 by 10 by $20 \mathrm{~cm}$ in size but could be larger if necessary. Test cell and test fluid changeouts would be kept to a minimum from a logistics standpoint, and the test fluids would typically be nontoxic. These characteristics should allow the AFM to accommodate a variety of fluid science experiments.

There are also plans for a fluids module that would be flown in the shuttle middeck lockers. The middeck lockers are more space and resource limited than the Spacelab lockers, but they offer the potential for more flight opportunities. This fluids module, like its Spacelab counterpart, would be able to accommodate different experiments by reconfiguring the hardware between flight opportunities. There would also be opportunities for on-orbit changeouts of

test hardware. Both of these shuttle-based fluids modules will offer valuable insight into the utility of the modular, multiuser concept.

Fluid Physics/Dynamics Facility (FP/DF). - Space Station Freedom's FP/DF is planned to be the cornerstone of the low-gravity fluids facilities. The FP/DF will have two double racks, one that contains facility subsystems, and one that contains experiment hardware; see figure 30. The facility support rack would contain subsystems or components that would be used by all or most fluid physics experiments: such systems as image processing, data acquisition and control, and electric power. The facility rack of the FP/DF will remain on orbit. The experiment rack, however, will be replaced every 1 to 2 years. One possible experiment rack configuration could use test cells that are aligned with the residual gravity vector by using, for example, an alignment mechanism in the rack. Another configuration could perform multiphase flow experiments.

These different modular, multiuser shuttle- and space station-based hardware systems of the future will be the tools with which a comprehensive lowgravity fluid physics program can be built. They should be able to accommodate a variety of experiment disciplines and a variety of differing experiment complexities, from very simple to highly complex. The goal of these new hardware designs is to encourage the participation of as many investigators and experiments as possible. Achieving this goal will require planning (which is under way and will continue into the foreseeable future) and wide participation from the fluids community.

\section{SUMMARY}

The world of low-gravity fluid dynamics is a diverse one. A small example of this diversity has been shown here in discussions of various types of lowgravity experiments. A variety of ground-based facilities (drop towers and 
aircraft) used to conduct low-gravity experiments were described, and a representative range of experimental capabilities was given for each facility.

Low-gravity facilities for in-space experimentation were also described. Presently, these consist solely of the space shuttle facilities. A menu of capabilities that are available to the researcher was described. The payload bay facilities range from the completely self-contained, relatively small GetAway-Special canisters, to the Materials Science Laboratory, to the larger Spacelab facilities that require crew interaction. The middeck facilities were also described and example experiments were given. Rather than describing facility capabilities, specific current, as well as past, in-space experiments were described in the hopes of giving the reader an idea of what can be done in these types of space-based facilities.

Future on-orbit fluids facilities were also discussed. The modular facility concept would offer a different approach to the current method of conducting individual low-gravity experiments. Rather than dedicated, single-purpose experiments, these facilities will be modular and multiuser in nature. An early version of such a facility is planned for Spacelab, with a more mature facility design slated for Space Station Freedom.

Even though low-gravity fluids research is entering its fourth decade, the lessons learned so far have raised as many (or more) questions as have been answered. Unfortunately, long-recognized areas of potential research have gone decades without adequate low-gravity data bases being generated. Continued and broader access to both ground-based and space-based low-gravity facilities is therefore extremely important. There is certainly no lack of potentially fruitful areas of low-gravity research - relative to both the fundamental sciences and to applied research. A well-balanced program of ground-based and space-based research will not only be mutually beneficial, but will also be the most efficient approach for a healthy and vibrant low-gravity fluids program.

\section{REFERENCES}

1. Monti, R., "Fluid Science Experiments and Facilities," Space Technology, Vol. 9, No. 1/2, 1989, pp. 33-40.

2. "Low-Gravity Fluid Physics: A Program Overview," NASA TM-103215, 1990.

3. Lekan, J., "Microgravity Research in NASA Ground-Based Facilities," AIAA Paper 89-0236, Jan. 1989. (Also, NASA TM-101397.)

4. Weislogel, M.M. and Ross, H.D., "Surface Settling in Partially Filled Containers Upon Step Reduction in Gravity," NASA TM-103641, 1990.

5. Chai, A.T., "Accurate Measurements of Contact Angles," AIAA Paper 89-0067, Jan. 1989 .

6. Ross, H.D., et al., "Behavior in Normal and Reduced Gravity of an Enclosed Liquid/Gas System with Nonuniform Heating from Above," AIAA Paper 89-0070, Jan. 1989. (Also, NASA TM-101471.) 
7. Cochran, T.H., et al., "An Experimental Investigation of Boiling in Normal and Zero Gravity," NASA TM X-52264, 1967.

8. Cochran, T.H. and Aydelott, J.C., "Effects of Sub-Cooling and Gravity Level on Boiling in the Discrete Bubble Region," NASA TN D-3449, 1966.

9. Merte, H., Jr., "Combined Roles of Buoyancy and Orientation in Nucleate Pool Boiling," Collected Papers in Heat Transfer, 1988, Vol. 2, K.T. Yang, ed., ASME, New York, 1988, pp. 179-186.

10. Symons, E.P., "Liquid Inflow to Partially Full Hemispherical-Ended Cylinders During Weightlessness," NASA TM X-1934, 1969.

11. Symons, E.P., Nussle, R.C., and Abdalla, K.L., "Liquid Inflow to Initially Empty Hemispherical-Ended Cylinders During Weightlessness," NASA TN D-4628, 1968.

12. Symons, E.P. and Staskus, J.V., "Interface Stability During Liquid Inflow to Partially Full, Hemispherical-Ended Cylinders During Weight lessness," NASA TM X-2348, 1971.

13. Labus, T.L. and Aydelott, J.C., "Gas-Jet Impingement Normal to a Liquid Surface," NASA TN D-6368, 1971.

14. Labus, T.L., "Cavity Stability During Gas-Jet Impingement on Liquid Surface in Weightlessness," NASA TN D-5976, 1970.

15. Heppner, D.B., King, C.D., and Littles, J.W., "Zero-G Experiments in TwoPhase Fluids Flow Regimes," ASME Paper 75-ENAS-24,' July 1975.

16. Dukler, A.E., et al., "Gas-Liquid Flow at Micro-gravity Conditions: Flow Patterns and Their Transitions," AIChE Workshop, Vol. 14, No. 4, July 8 , 1988, pp. 389-400.

17. Kachnik, L., et al., "A Microgravity Boiling and Convective Condensation Experiment," ASME Paper 87-WA/HT-12, Dec. 1987.

18. Hill, D.G., et al., "Reduced Gravity and Ground Testing of a Two-Phase Thermal Management System for Large Spacecraft," SAE Paper 881084, July 1988 .

19. "Tank Pressure Control Experiment on the Space Shuttle," NASA TM-102313, 1989.

20. Thomas, S., "Thermocapillary Flow and Gaseous Convection in Micro-gravity: Results from GAS Payload G-0518," 1985 Get-Away-Special Experimenter's Symposium, L.R. Thomas and F.L. Mosier, eds., NASA CP-2401, 1985, PP. 293-301.

21. Ku, J., et al., "Capillary Pumped Loop GAS and Hitchhiker Flight Experiments," AIAA Paper 86-1249, June 1986.

22. Glicksman, M.E., et al., "Dendritic Solidification Under Microgravity Conditions," AIAA Paper 88-0248, Jan. 1988. 
23. Gammon, R.W., "Photon Correlation Light Scattering Apparatus for the Space Shuttle," presented at the Society of Photo-0ptical Instrumentation Engineers (SPIE), Aug. 1987.

24. Wang, T.G., et al., "The Dynamics of Free Liquid Drops," NASA Microgravity Sciences and Applications Flight Programs, January-March 1987, Selected Papers, Vol. 2, NASA TM-4069-VOL-2, 1987, pp. 739-761.

25. McCay, T.D. et al., "Convective Instabilities During Directional Solidification," Journal of Thermophysics and Heat Transfer, Vol. 3, No. 3, July 1989, pp. 345-350.

26. Kamotani, Y. and 0strach, S., "Design of a Thermocapillary Flow Experiment in Reduced Gravity," Journal of Thermophysics and Heat Transfer, Vol. 1, No. 1, Jan. 1987, pp. 83-89.

27. Lind, M.D., "Thermocapillary Flows in Floating-Zone Processes," AIAA Paper 87-0618, Jan. 1987.

28. Tegart, J., "Storable Fluid Management Demonstration - Flight 1, Dec. 1985 Progress Report," Martin Marietta/Denver Aerospace Division, Report No. R85-48602-001, 1985.

29. Radcliffe, M.D., et al., "Organic Crystal Growth in Low Earth Orbit," Journal of Crystal Growth, Vol. 92, No. 3-4, 1988, pp. 581-590.

30. Butler, D. and McIntosh, R., "Development and Integration of the Capillary Pumped Loop GAS and Hitchhiker Flight Experiments," NASA TM-100756, 1990. 


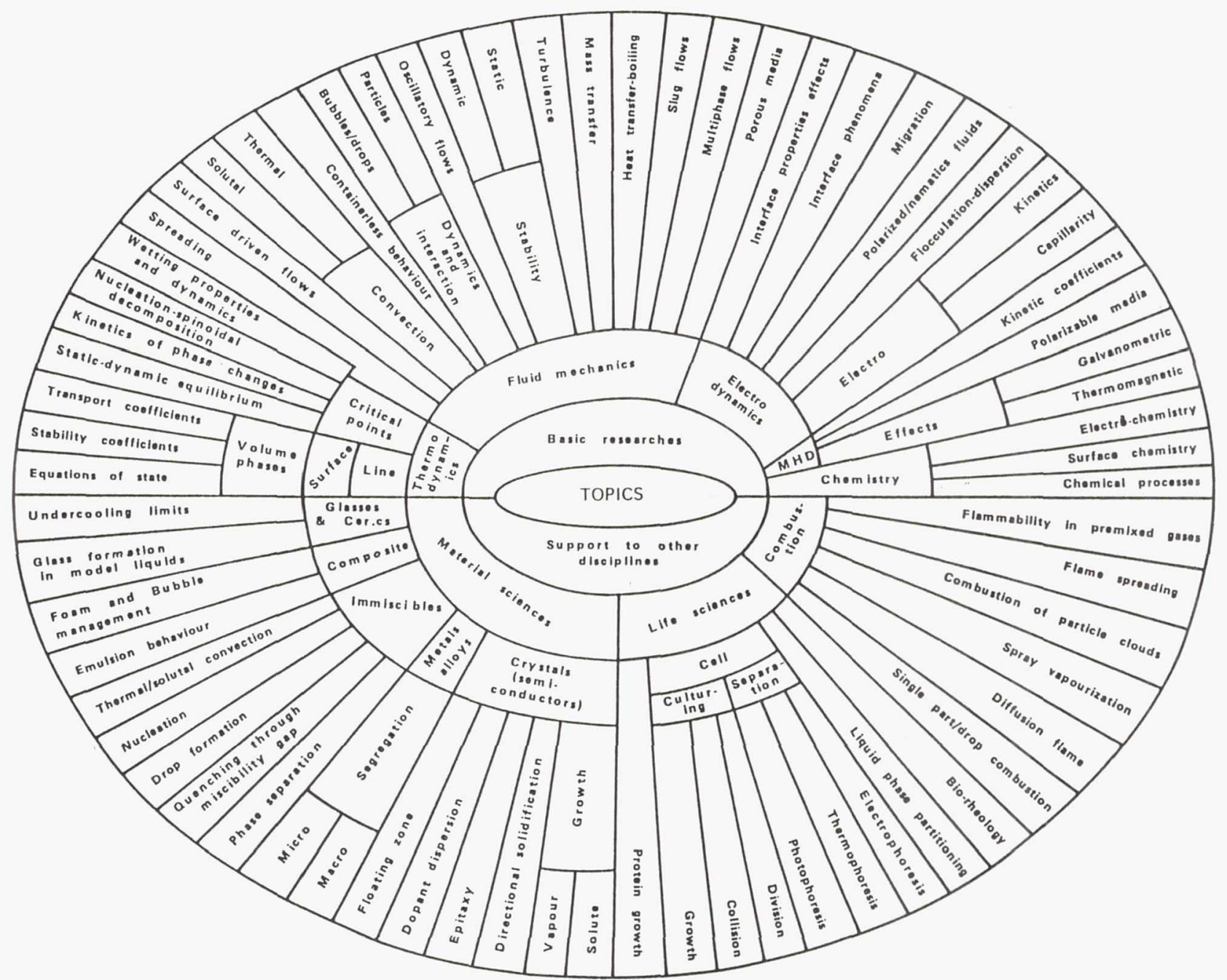

FIGURE 1. - ENVELOPE OF AREAS OF INTEREST FOR FLUID SCIENCE EXPERIMENTATION IN MICROGRAVITY. (FROM REFERENCE 1.) 


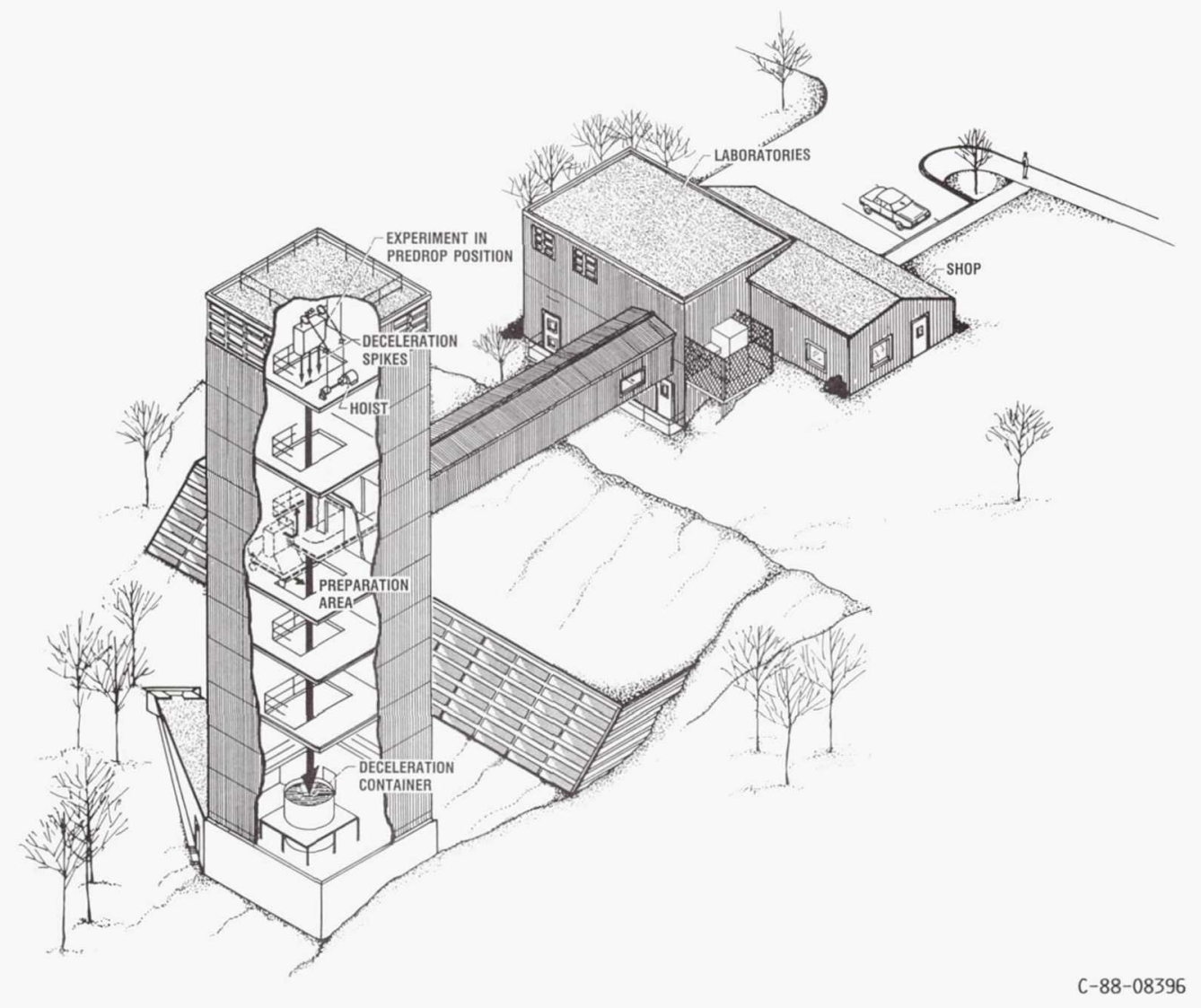

(a) FACILITY.

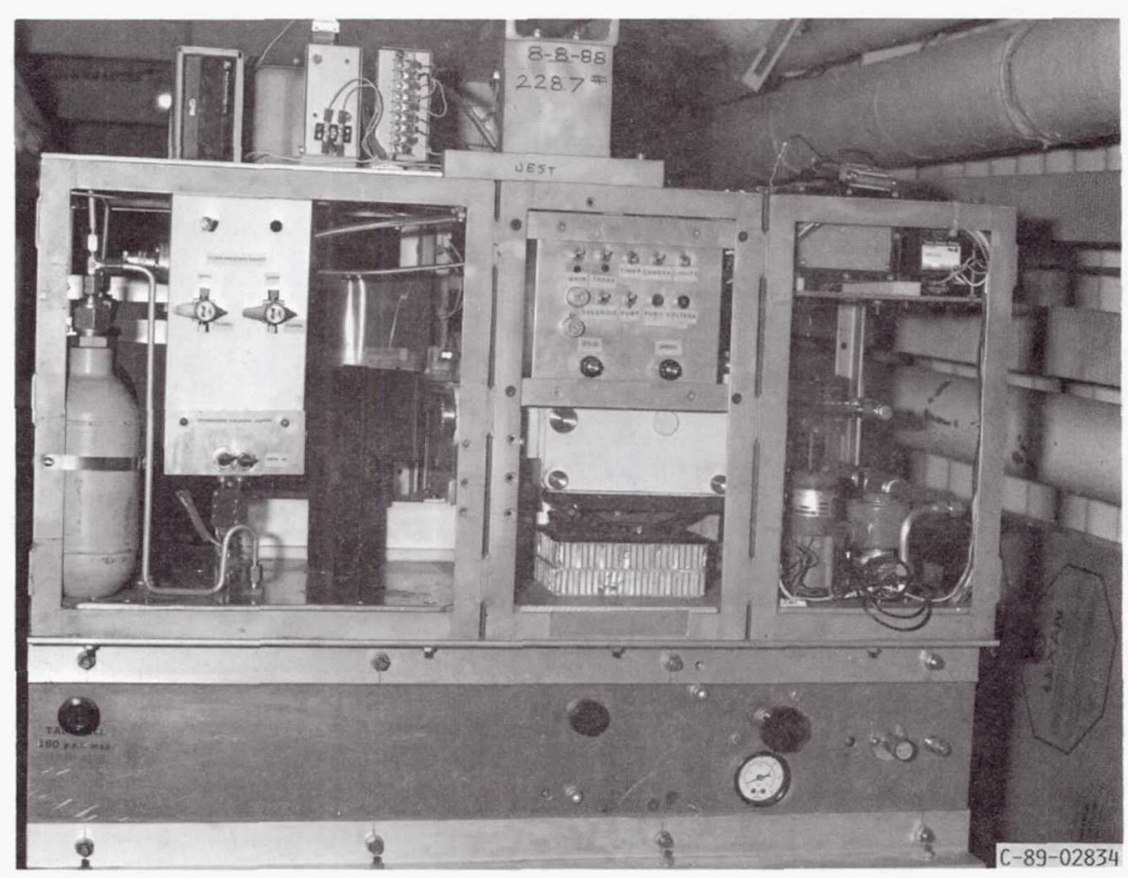

(b) EXPERIMENT PACKAGE (TWO-PHASE FLOWTHROUGH FITTINGS).

FIGURE 2. - NASA LEWIS RESEARCH CENTER'S 2.2-SECOND DROP TOWER. (FROM REFERENCE 2.) 


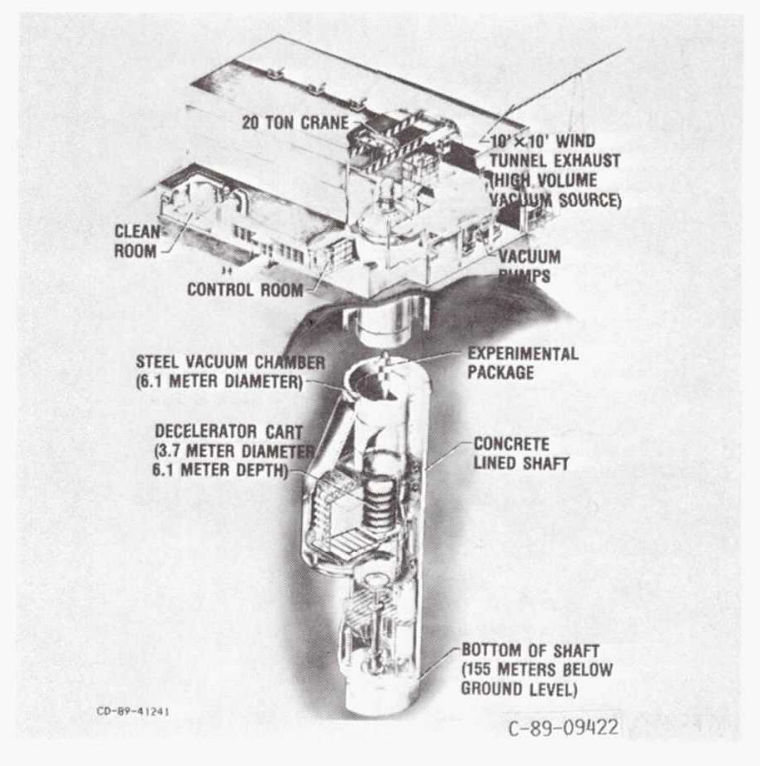

(a) FACILITY.

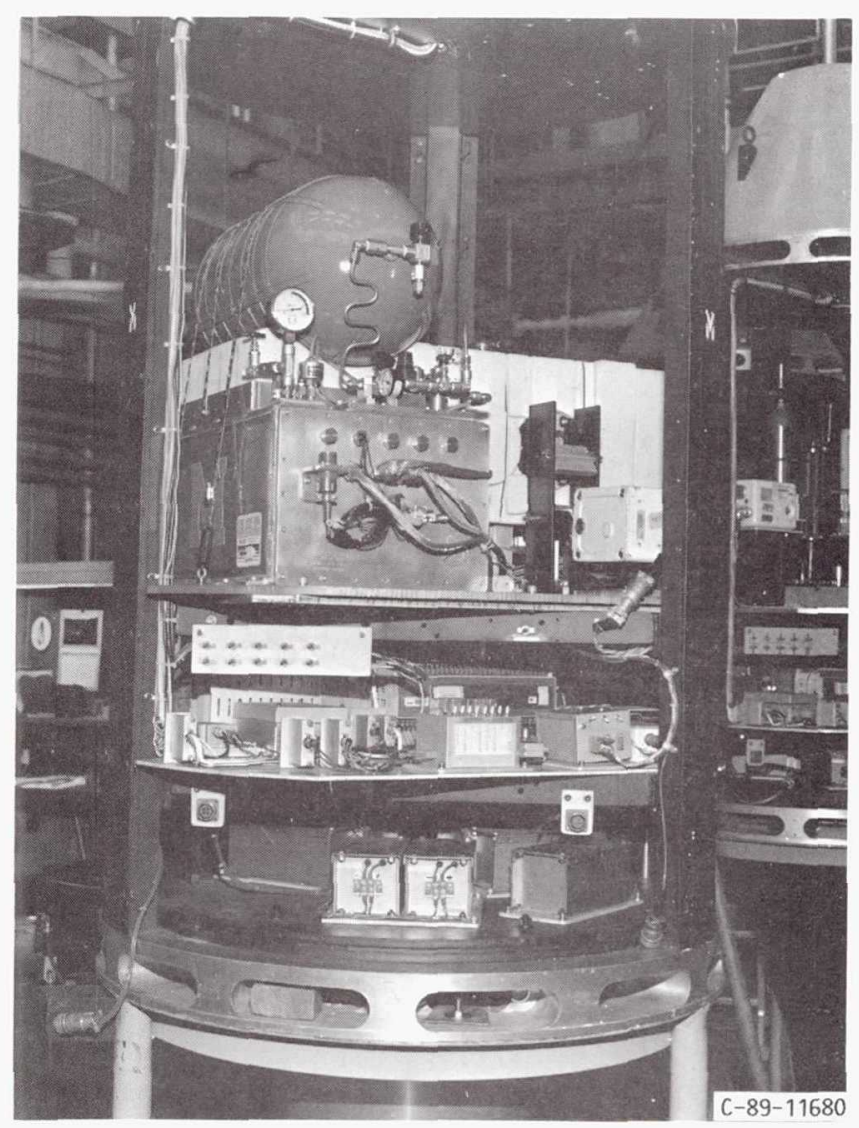

(b) EXPERIMENT PACKAGE (POOL BOILING EXPERIMENT).

FIGURE 3. - NASA LEWIS RESEARCH CENTER'S ZERO-GRAVITY FACILITY. (FROM REFERENCE 2.)

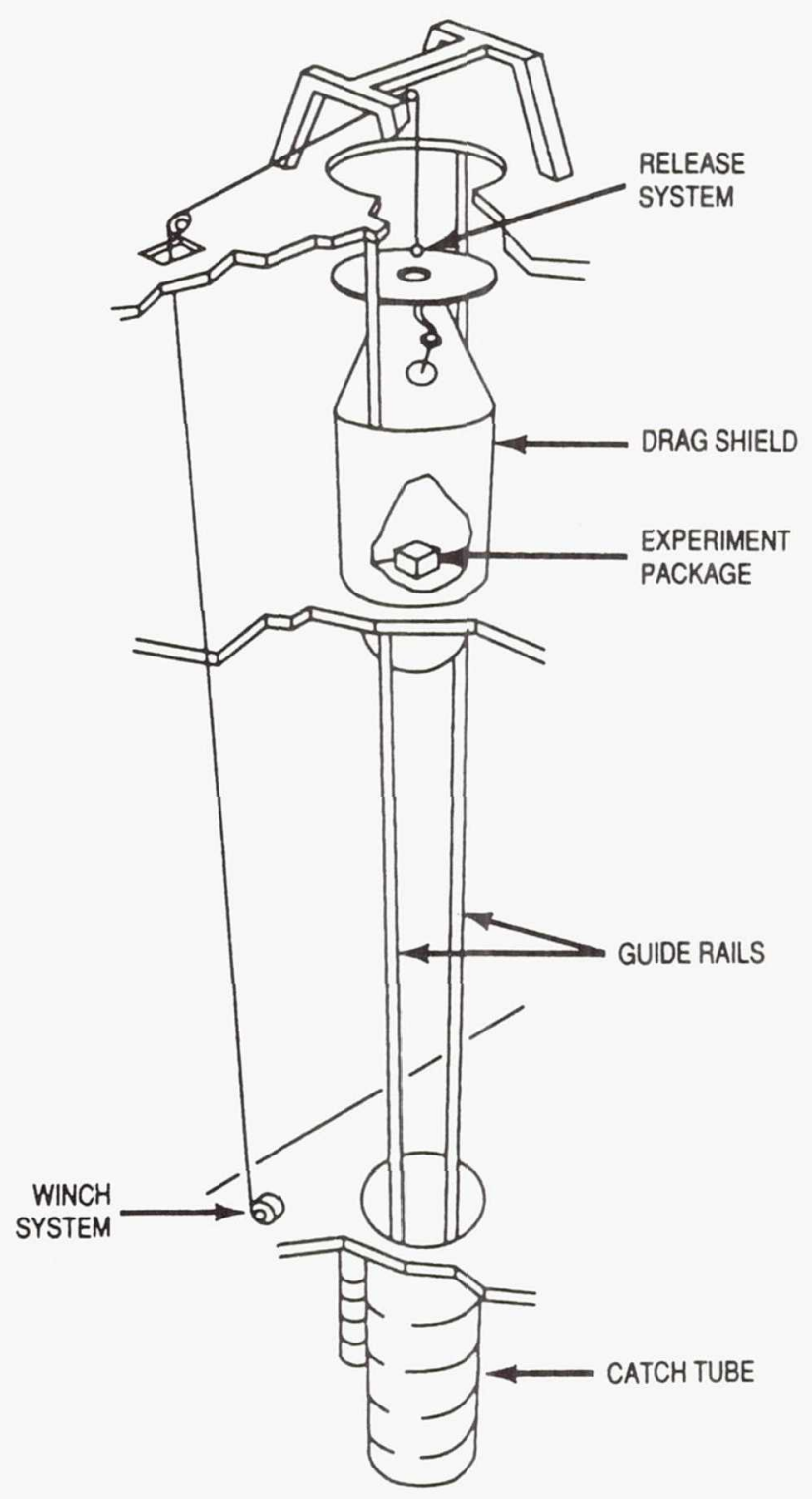

FIGURE 4. - NASA MARSHALL SPACE FLIGHT CENIER'S 100-METER DROP TOWER. (FROM REFERENCE 3.) 

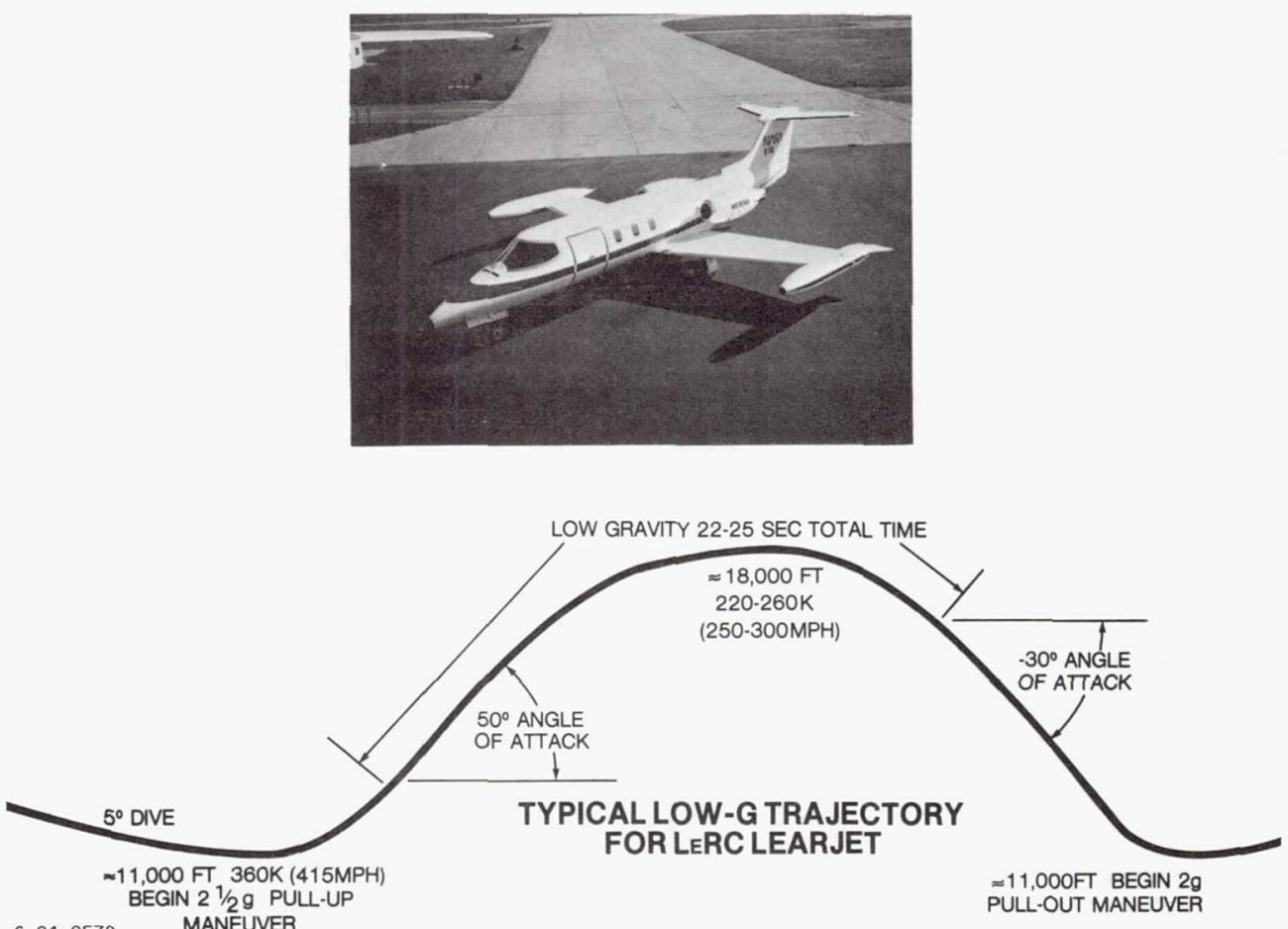
C-81-2538 MANEUVER

$\approx 11,000 F T$ BEGIN 2

FIGURE 5. - LEWIS AIRBORNE LOW-GRAVITY FACILITY - MODEL 25 LEARJET ANI) IYPICAL LOW-GRAVITY TRAJECTORY. (FROM REFERENCE 2. 


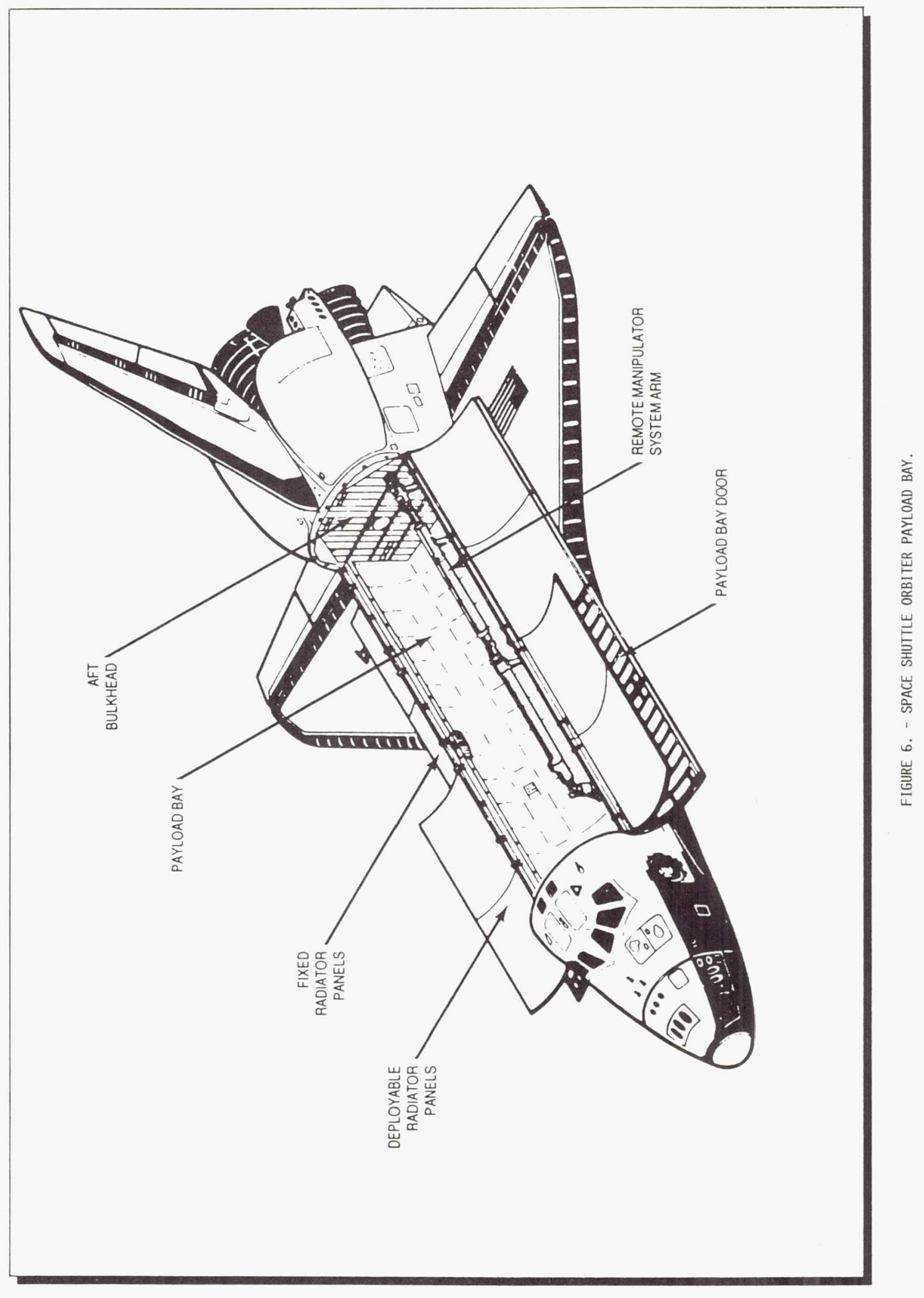




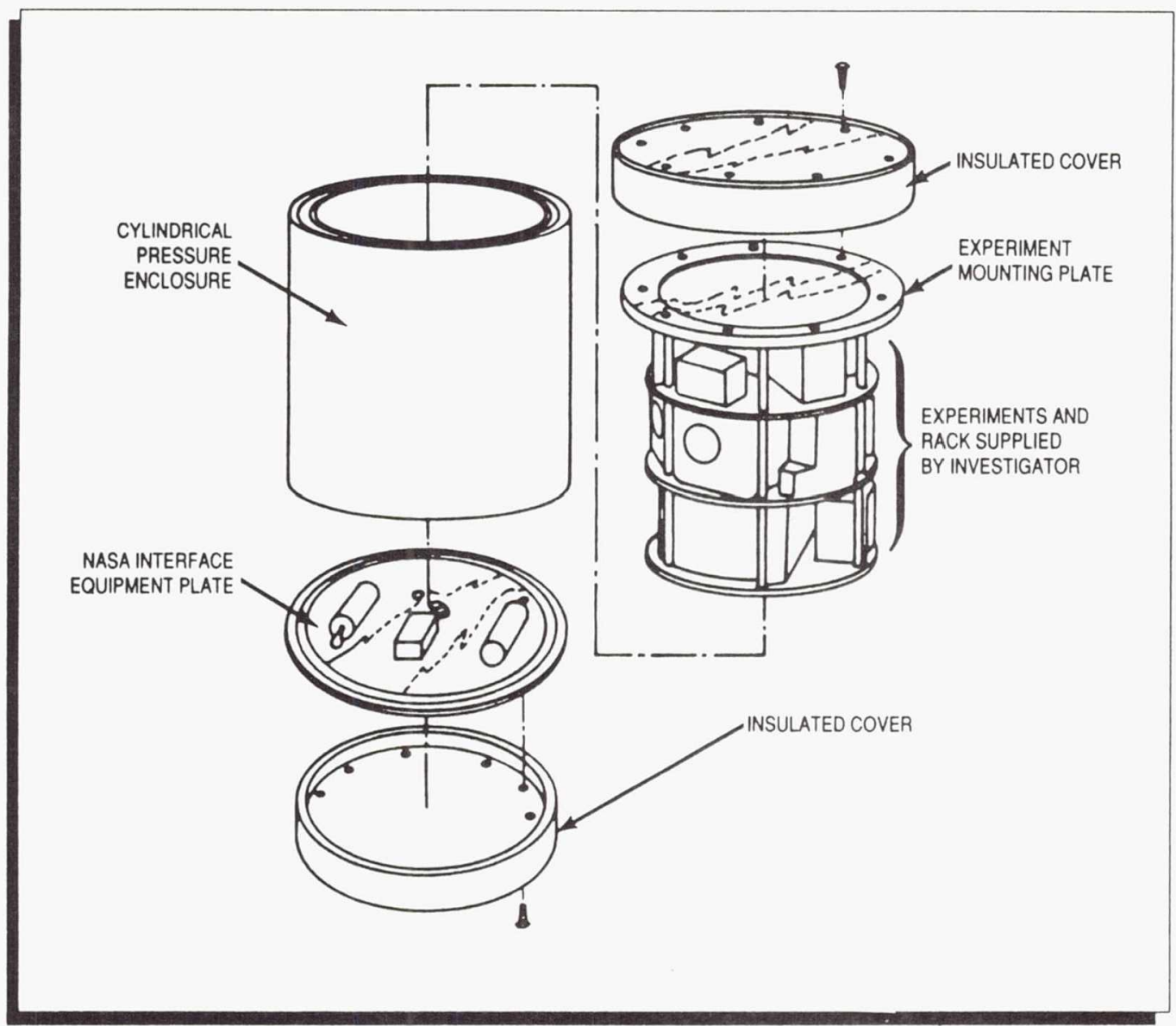

FIGURE 7. - GET-AWAY-SPECIAL CANISIER.

\section{DESCRIPTION}

- Low-g fluid mixing experiment on STS

- Freon in a plexiglass tank is thermally stratified by heaters and then mixed by an axial jet mixer

- Temperature, pressure, and video data
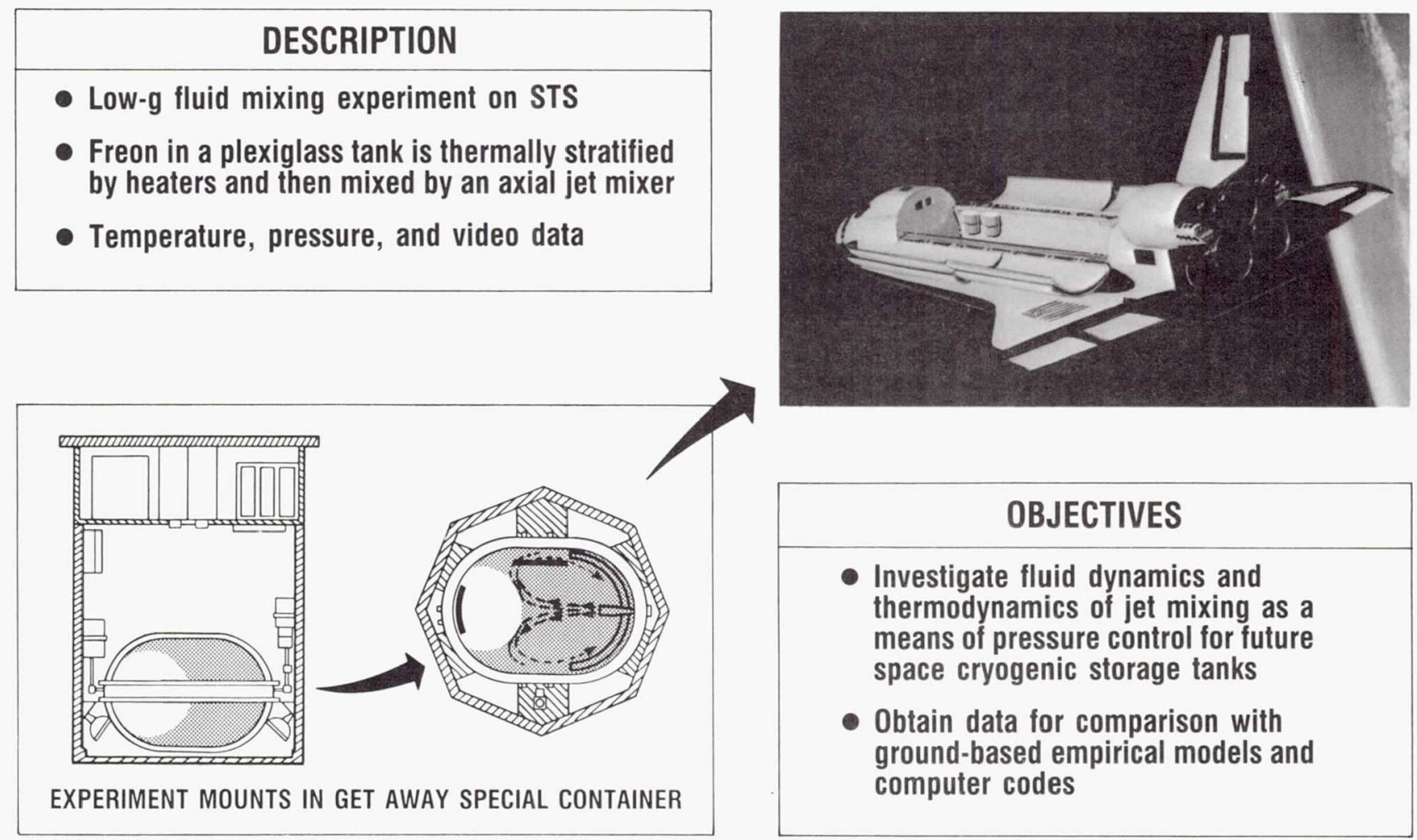

\section{OBJECTIVES}

- Investigate fluid dynamics and thermodynamics of jet mixing as a means of pressure control for future space cryogenic storage tanks

- Obtain data for comparison with ground-based empirical models and computer codes 


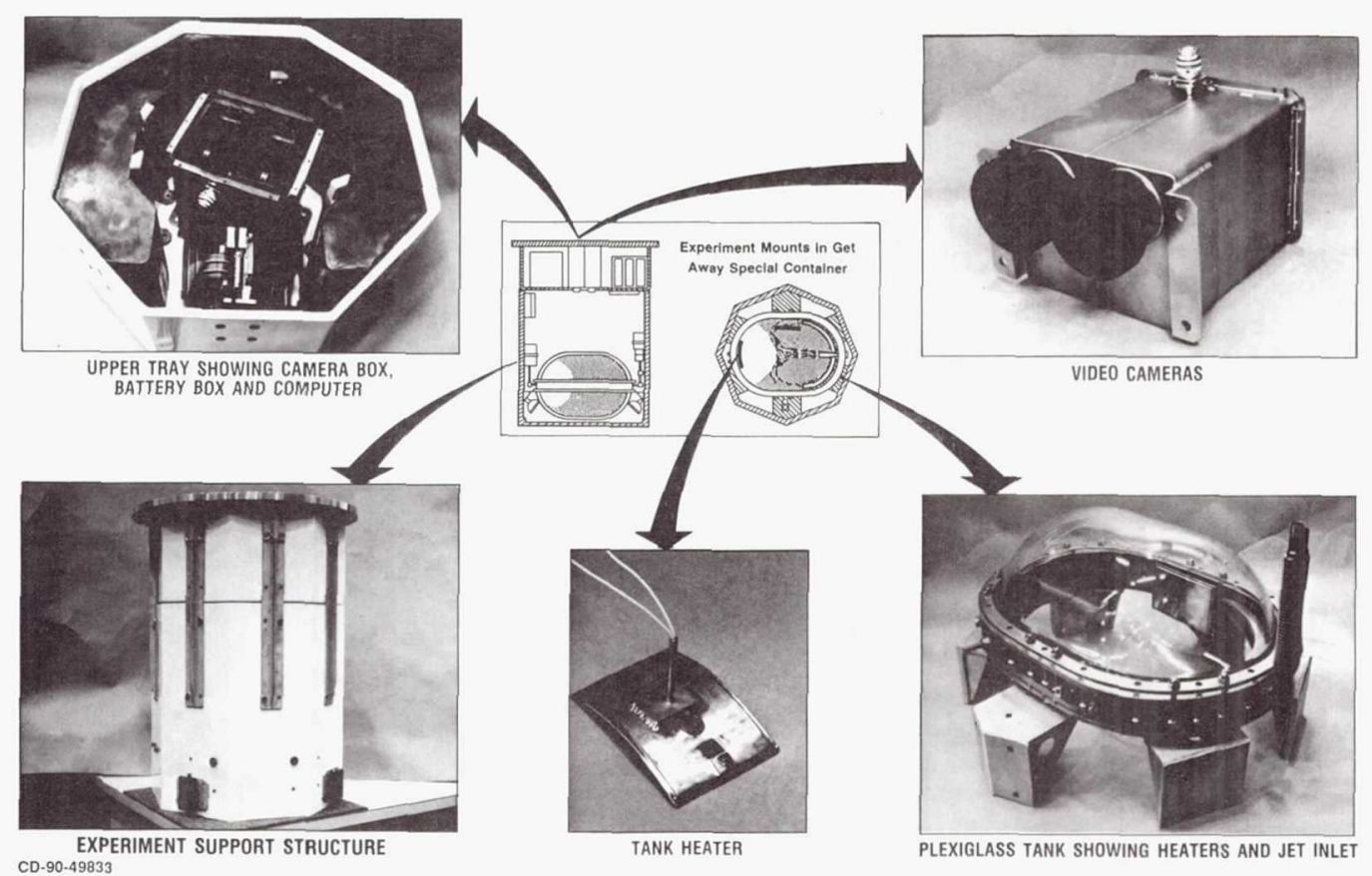

FIGURE 9. - TPCE FLIGHT HARDWARE.

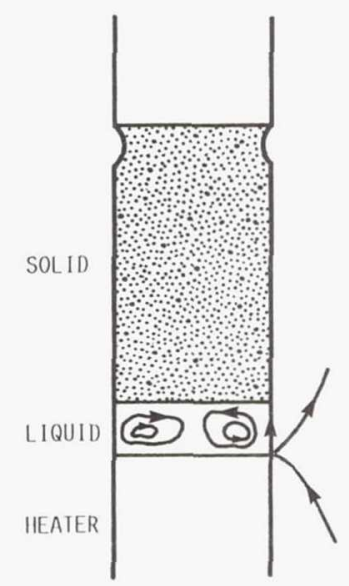

(a) TIME, $2.5 \mathrm{MIN}$.

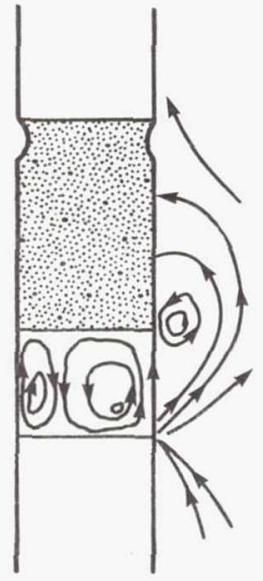

(b) TIML, $4.5 \mathrm{MIII}$

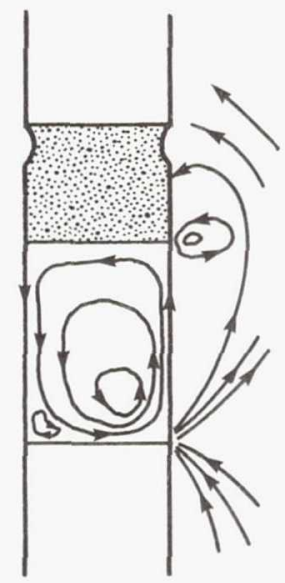

(c) TIME, $7.5 \mathrm{MIN}$.

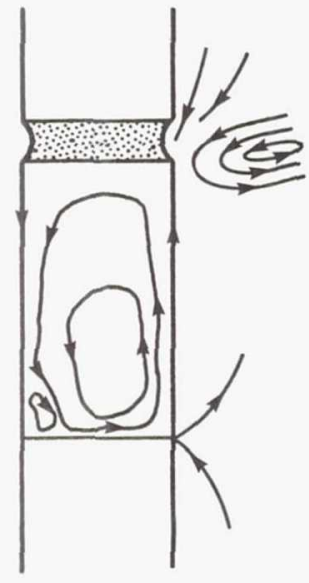

(d) TIME, $13.5 \mathrm{MIN}$,

FIGURE 10. - EXTERNAL GAS VORTICES GENLRAIED IN THERMOCAPJLLARY FLOW EXPERIMENI (GAS-0518). (FROM REFERENCE 20.) 


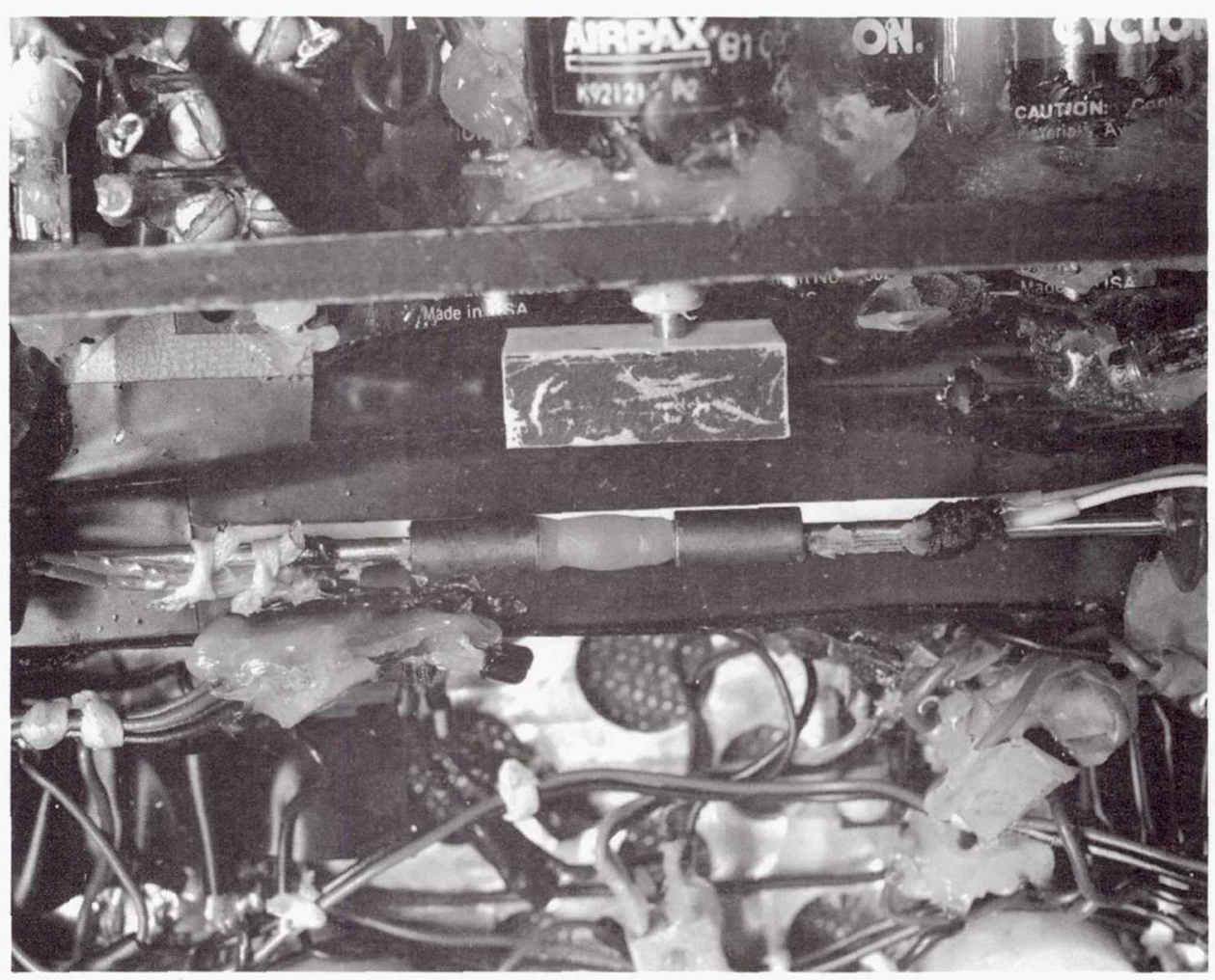

FIGURE 11. - THERMOCAPILLARY FLOW EXPERIMENT (GAS-0518) HARDWARE.

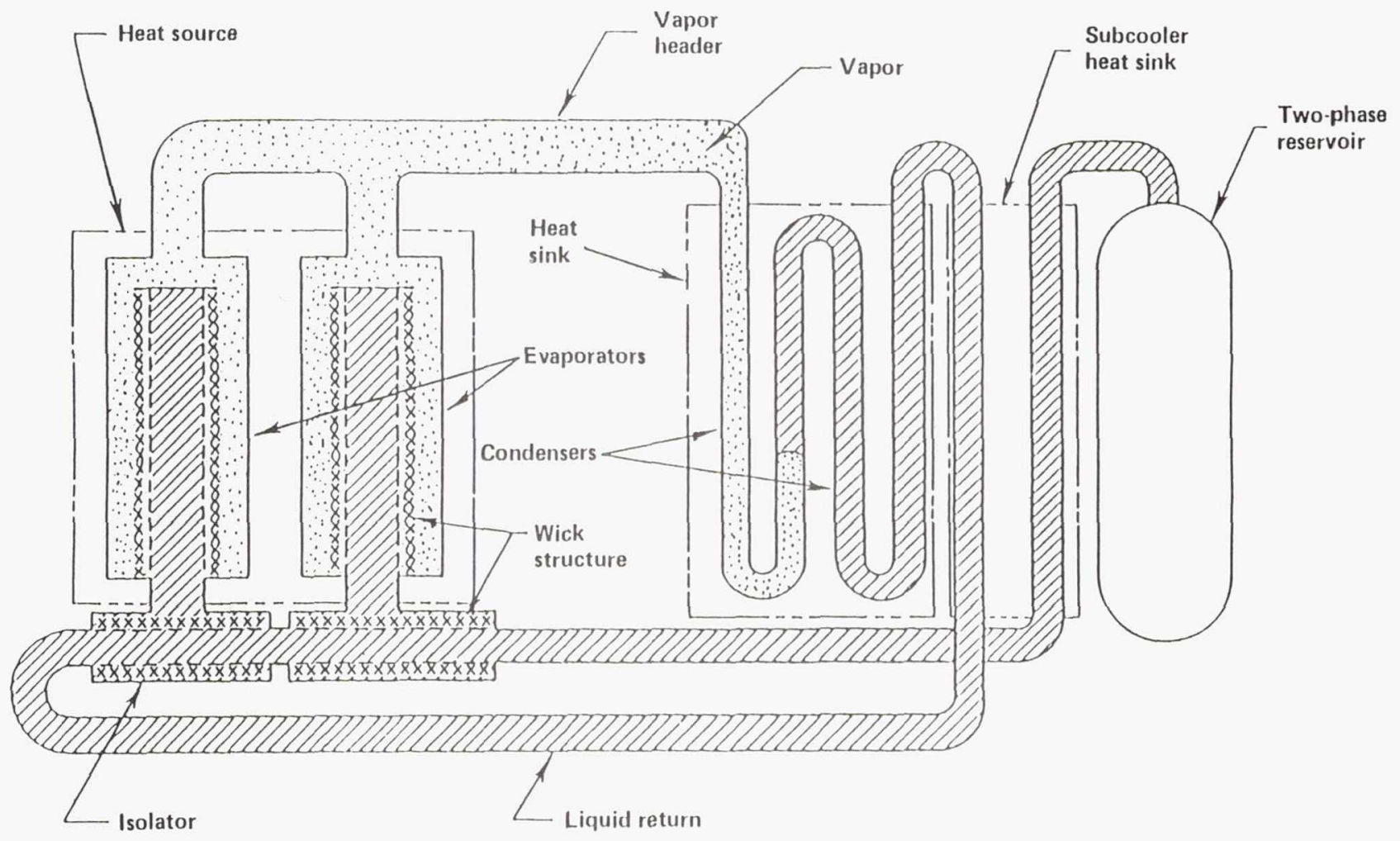

FIGURE 12. - FUnCTIONAL SCHEMATIC OF CAPILLARY PUMPED LOOP (CPL) EXPERIMENT. (FROM REFERENCE 30.) 


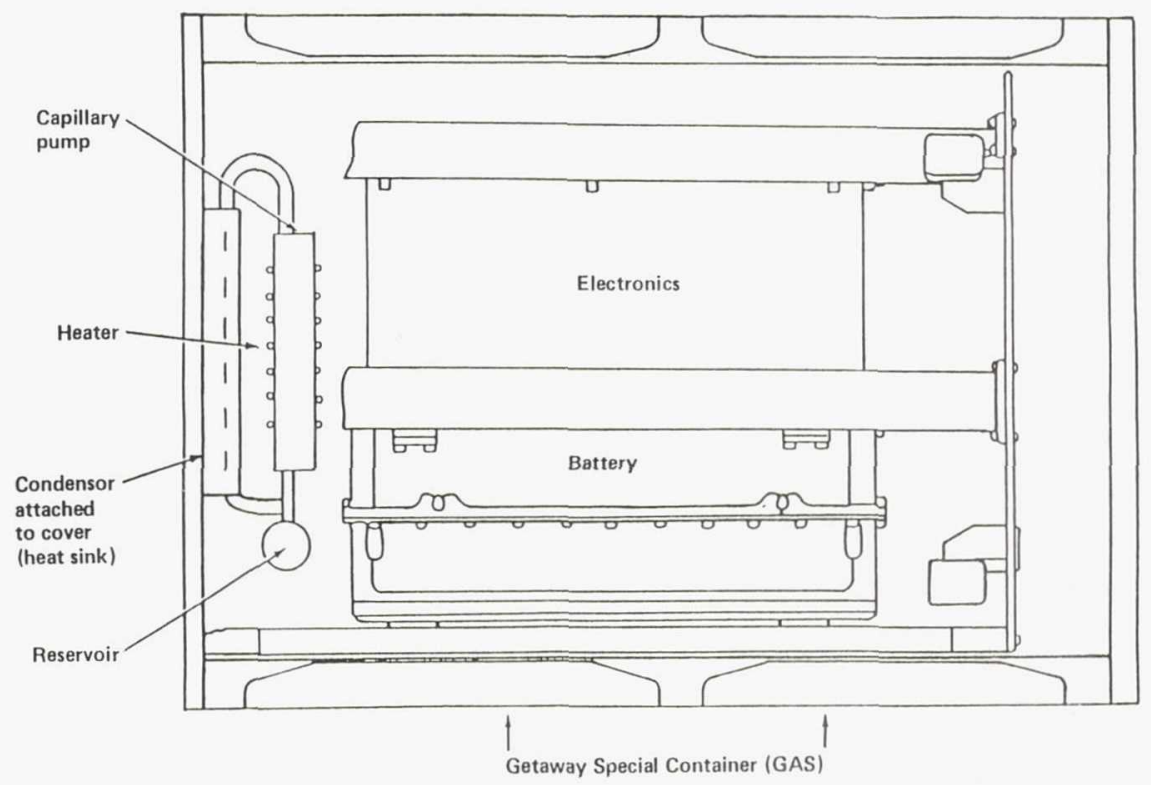

(a) CAPILLARY PUMP-PRIMING EXPERIMENT IN GAS CONTAINER.

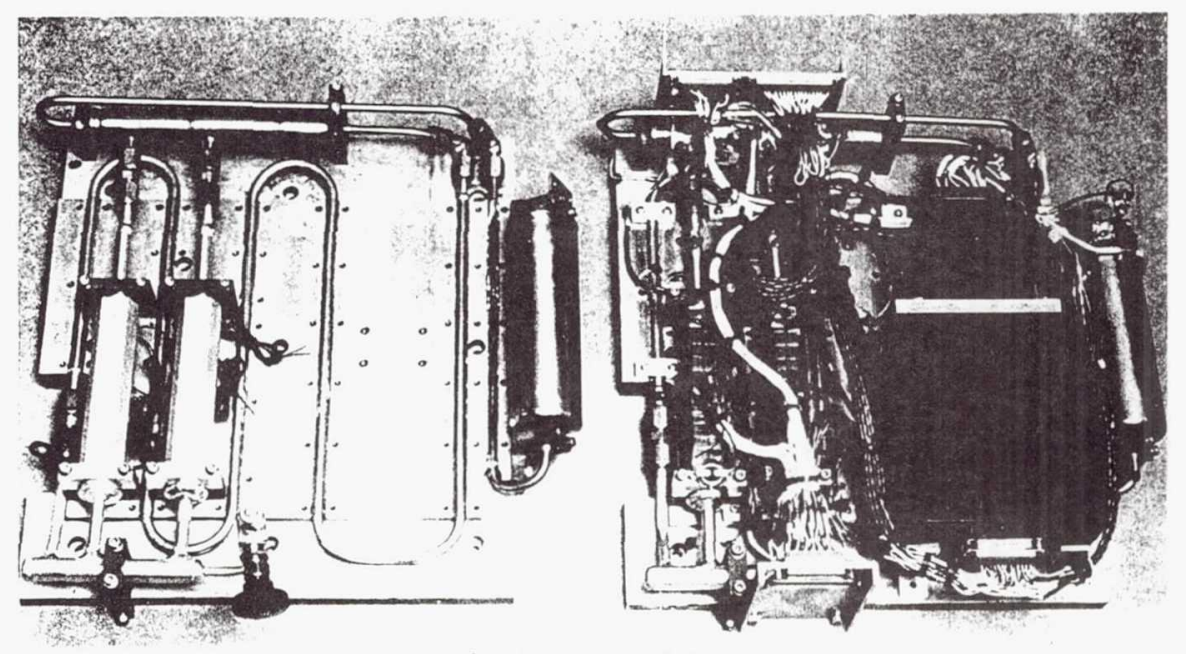

(b) CPL FLOW HARDWARE.

FIGURE 13. - DETAILS OF CPL GAS HARDWARE. (FROM REFERENCE 30.) 


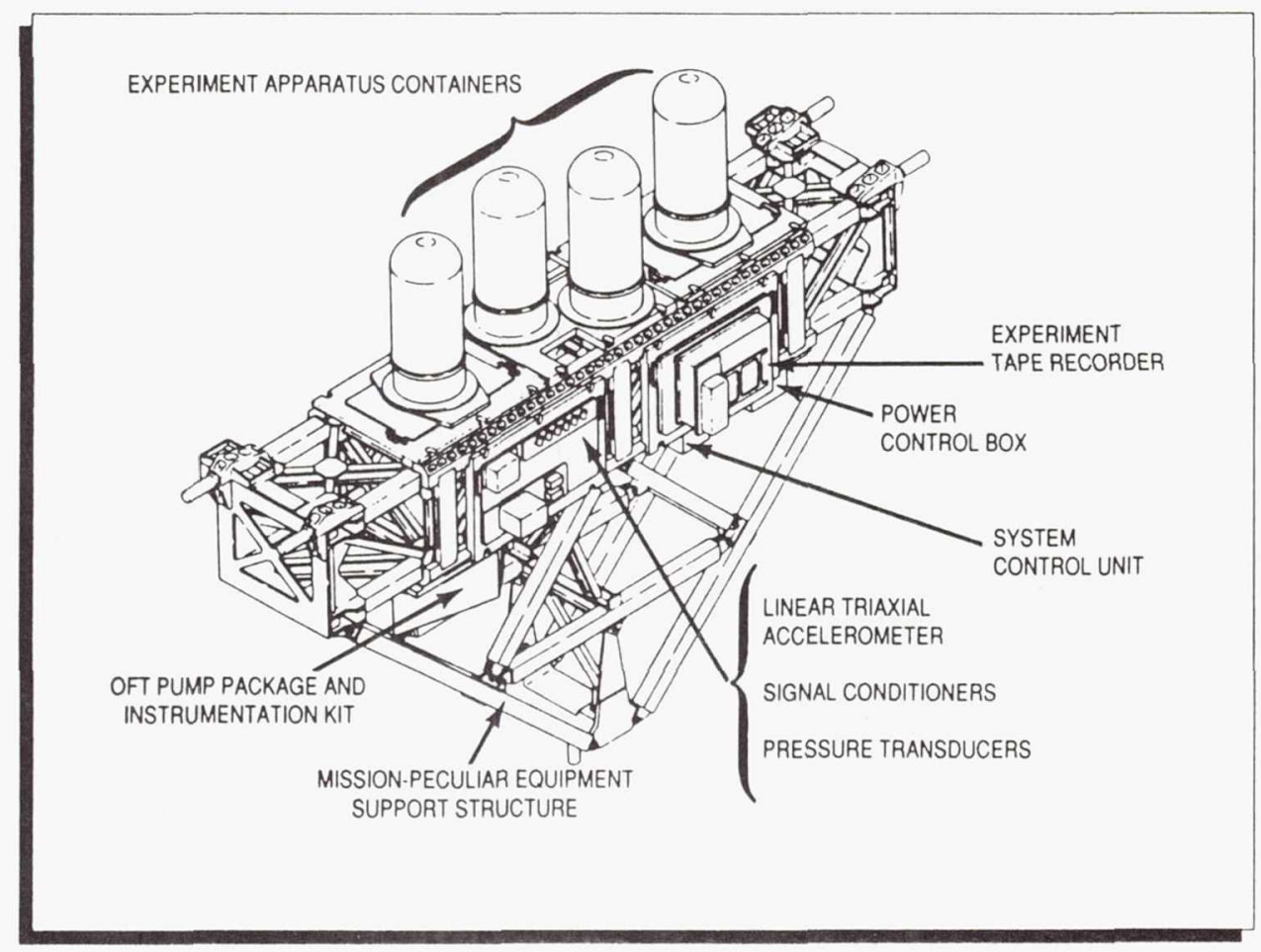

FIGURE 14. - MATERIALS SCIENCE LABORATORY (MSL).



FIGURE 15. - ISOTHERMAL DENDRITIC GROWTH EXPERIMENT FOR SPACE SHUTTLE MISSION USMP. 


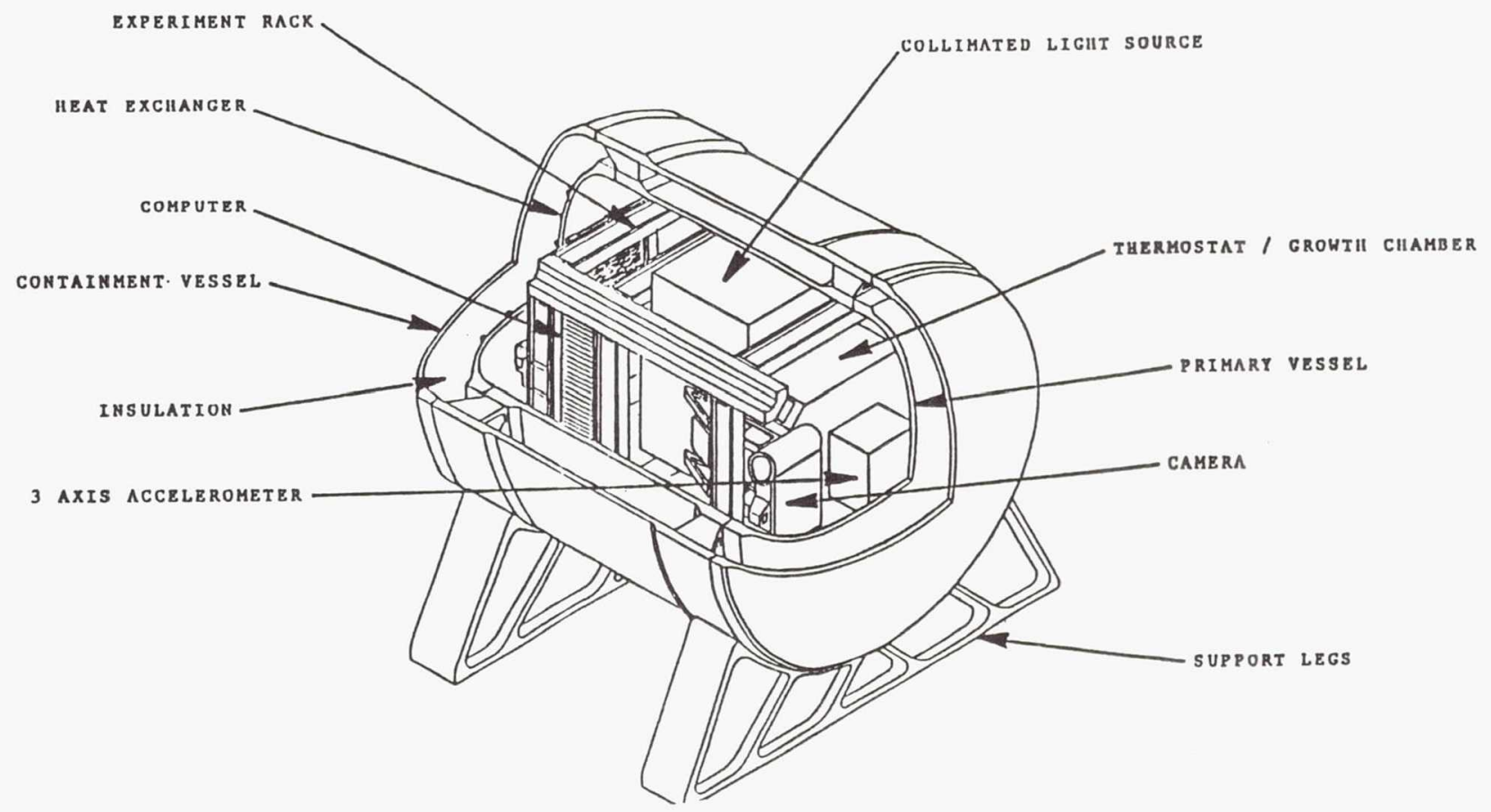

(a) CUTAWAY OF IDGE APPARATUS SHOWING MAJOR COMPONENTS. APPROXIMATELY 40 IN. LONG BY 35 IN. IN DIAMETER AND WEIGHING 680 LB.

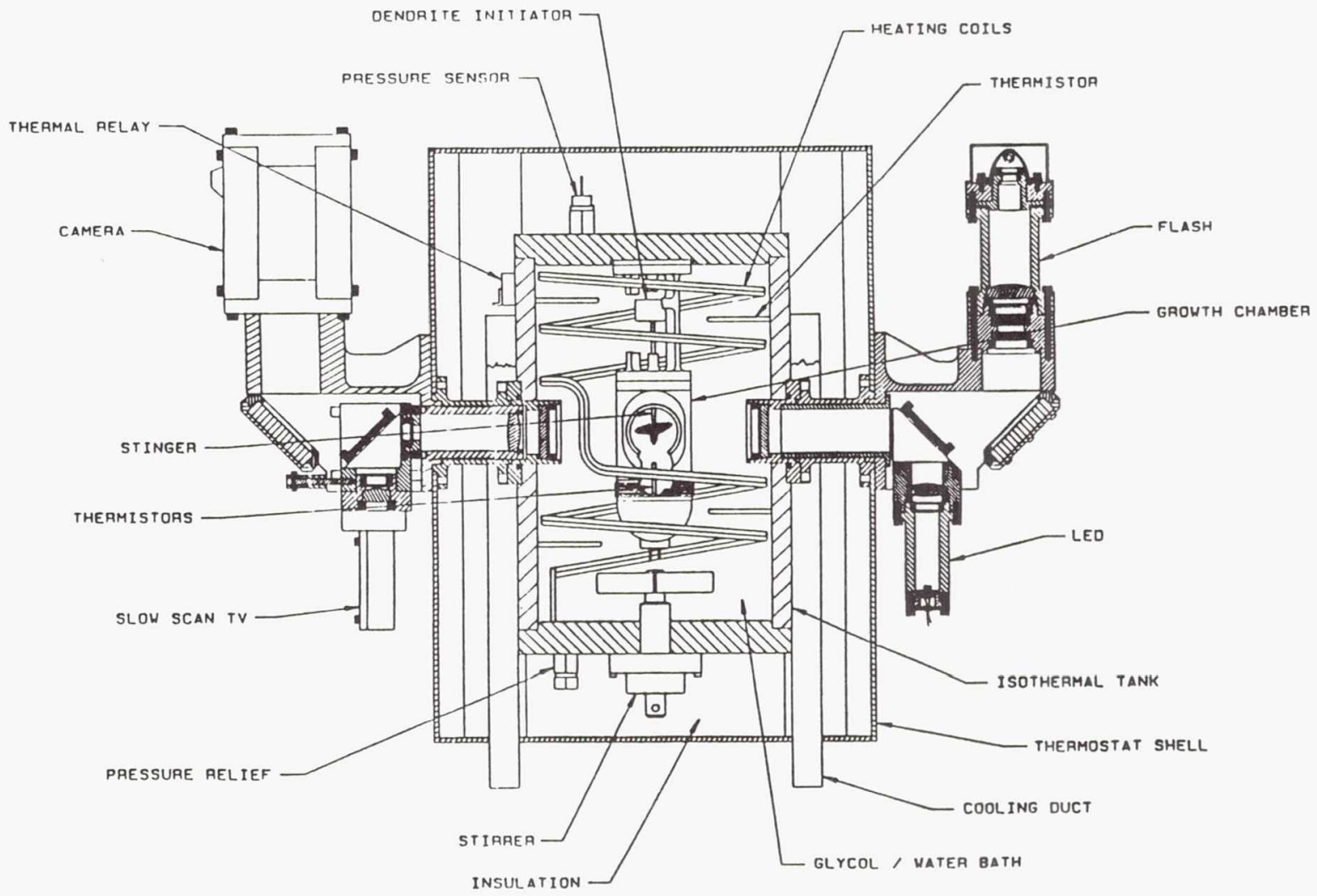

(b) IDGE THERMOSTAT, 35-MM CAMERA, AND SLOW-SCAN TELEVISION CAMERA.

FIGURE 16. - DETAILS OF IDGE MODULE. 


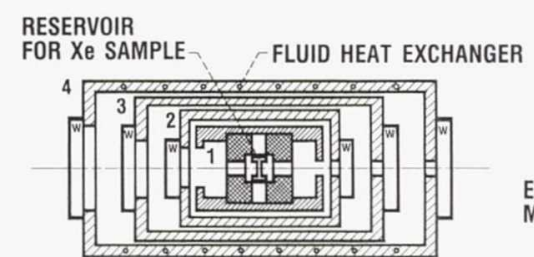

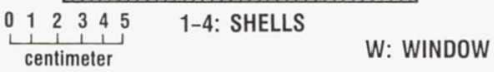
THERMOSTAT AND SAMPLE CELL
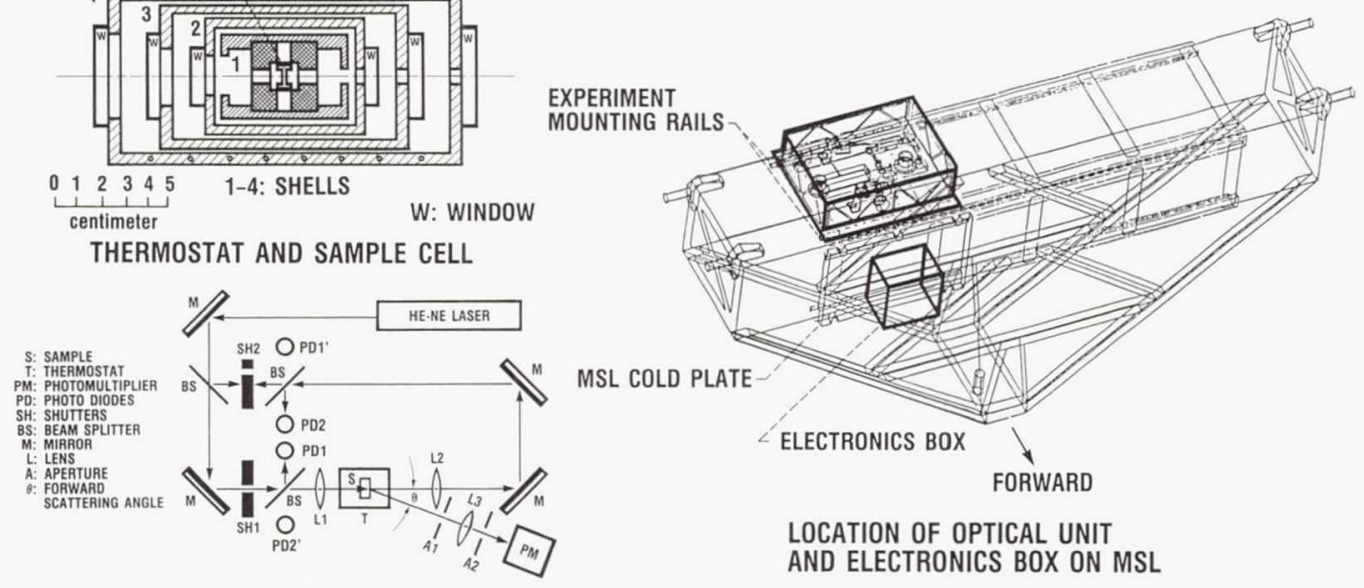
PROPOSED OPTICAL LAYOUT

FIGURE 17. - CRITICAL FLUID LIGHT SCATTERING EXPERIMENT (CFLSE) IN SPACE SHUTTLE MSL FACILITY. 


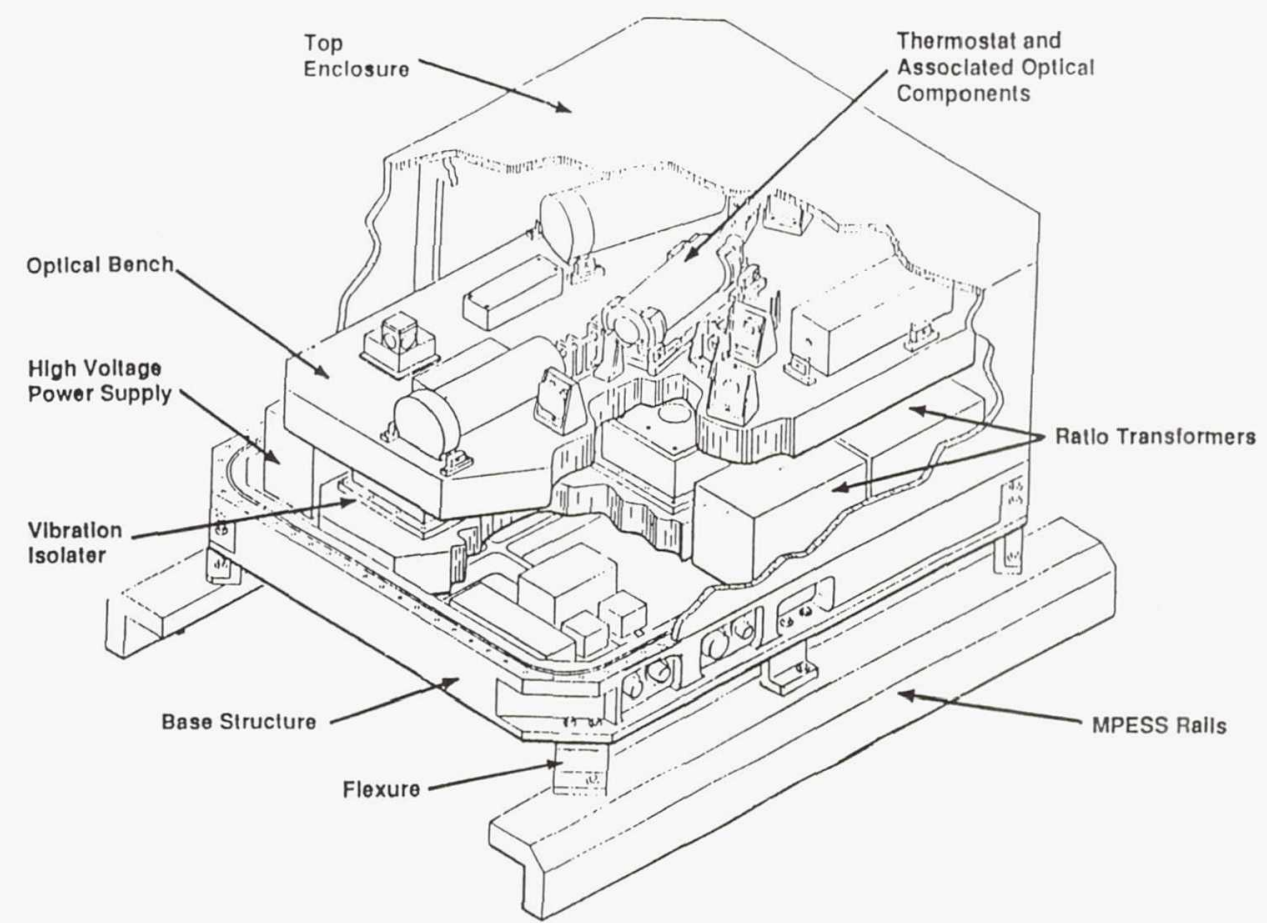

(a) CUTAWAY OF OPTIC MODULE.

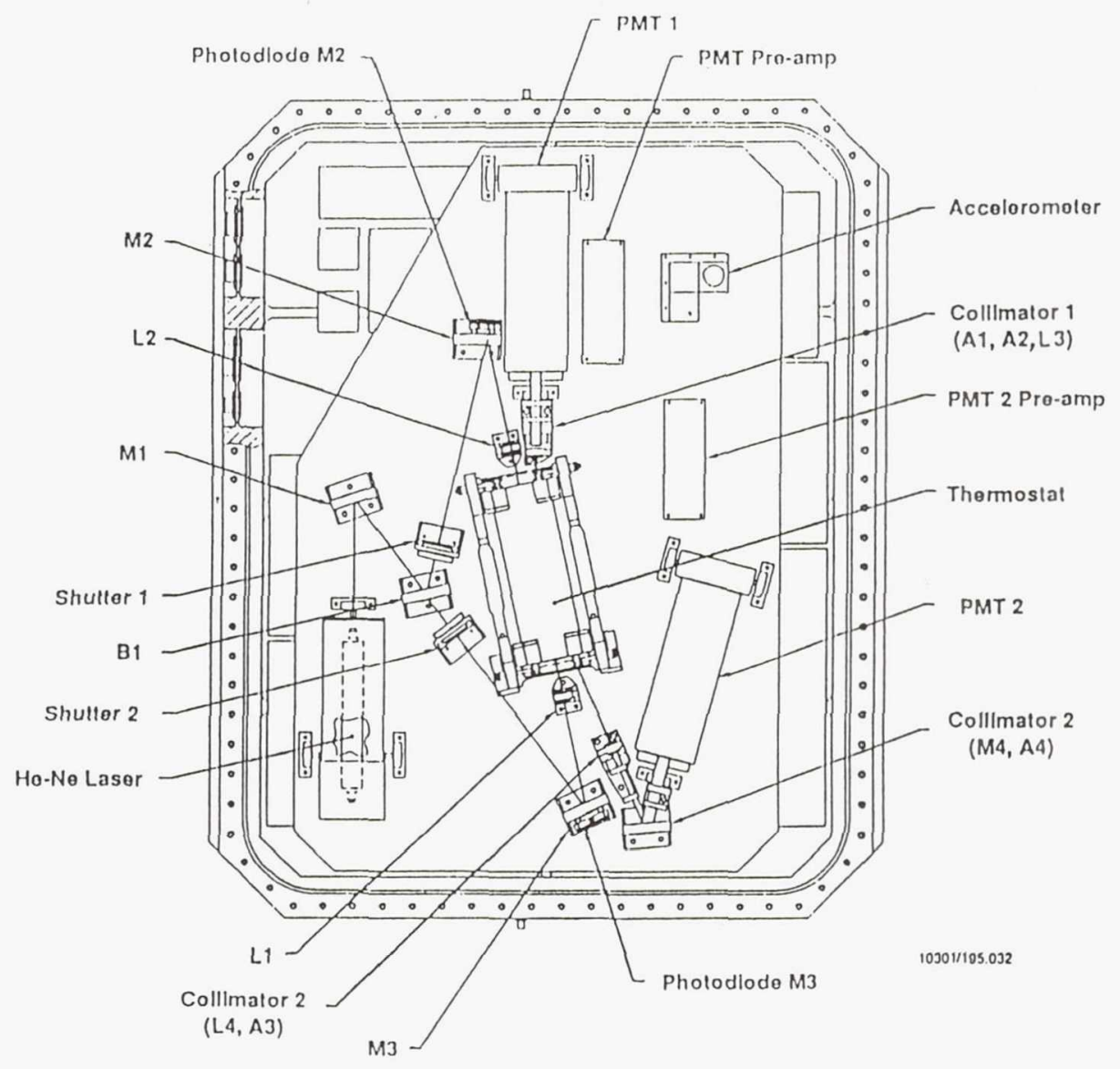

(b) COMPONENTS OF OPTIC MODULE.

FIGURE 18. - DETAILS OF CFLSE MODULE. 


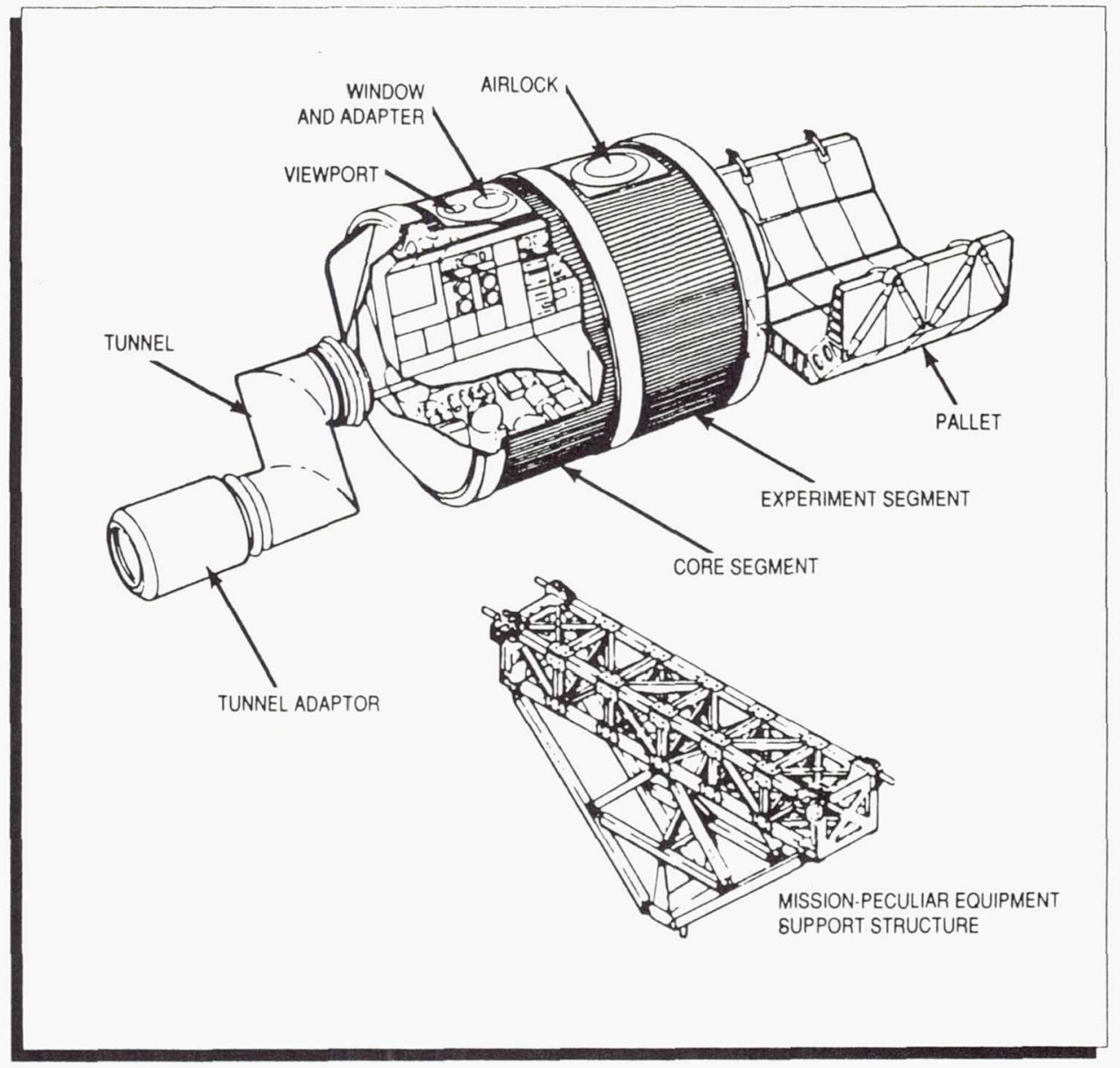

FIGURE 19. - MAIN COMPONENTS OF SPACE SHUTTLE'S SPACELAB FACILITY.
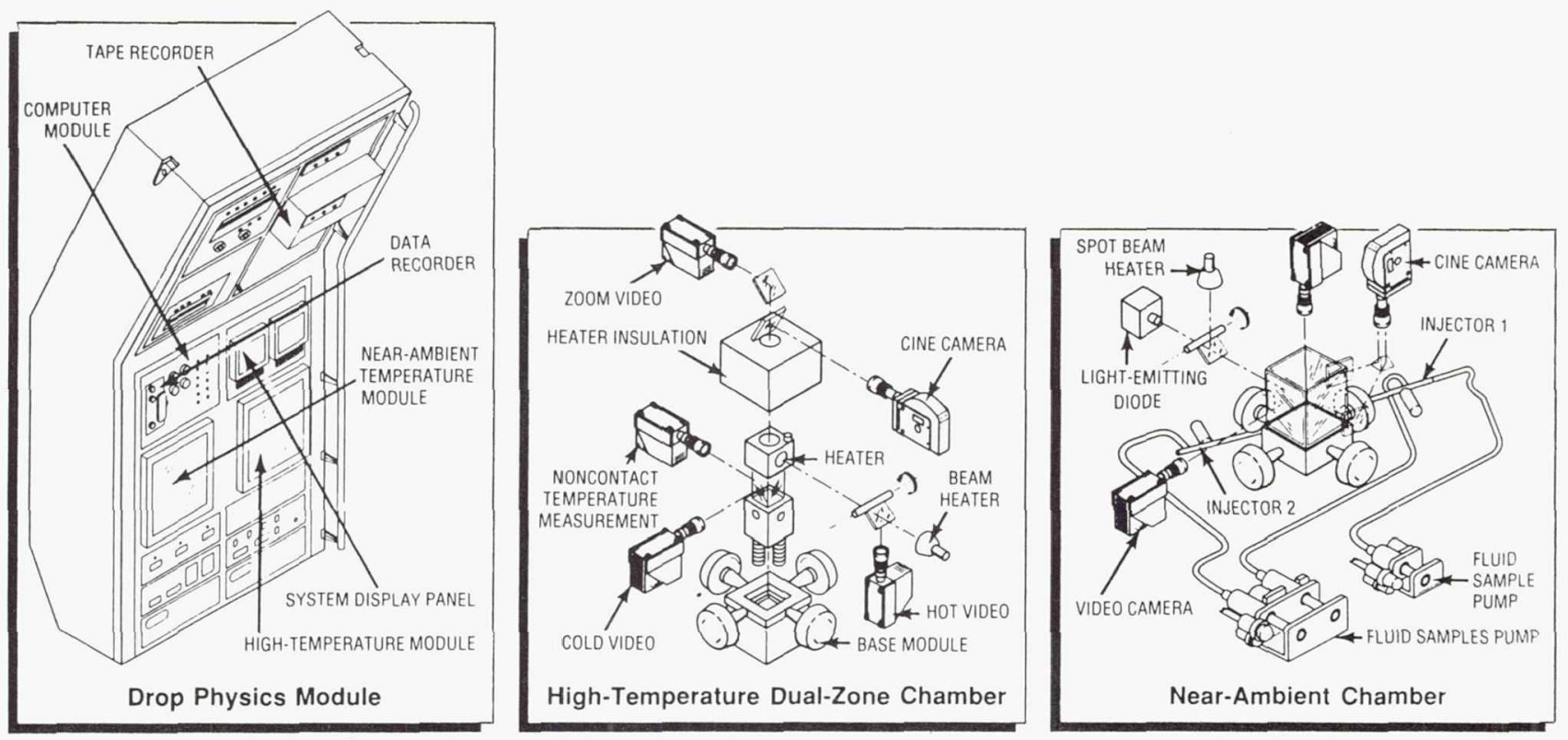

FIGURE 20. - DROP PHYSICS MODULE (DPM). 


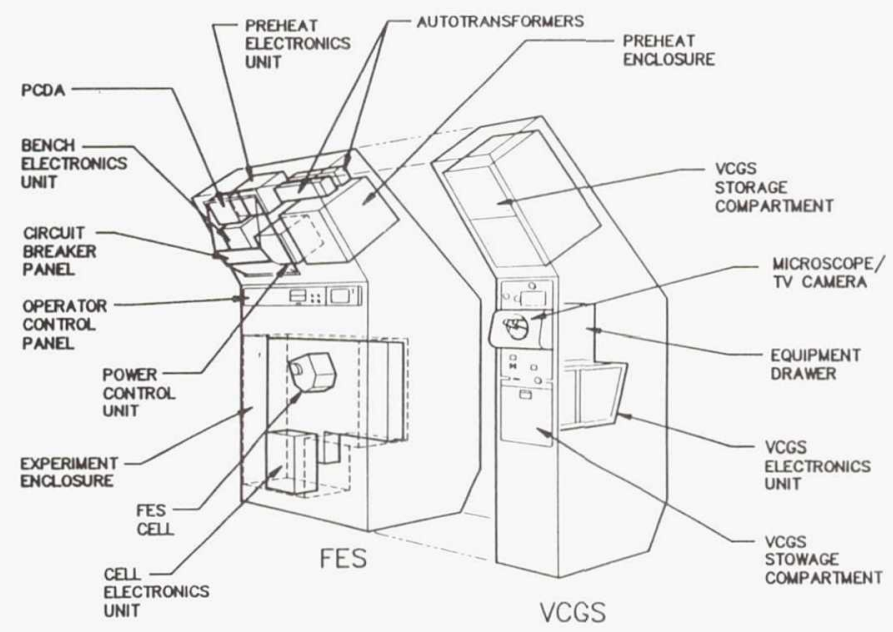

(a) FACILITY SCHEMATIC.

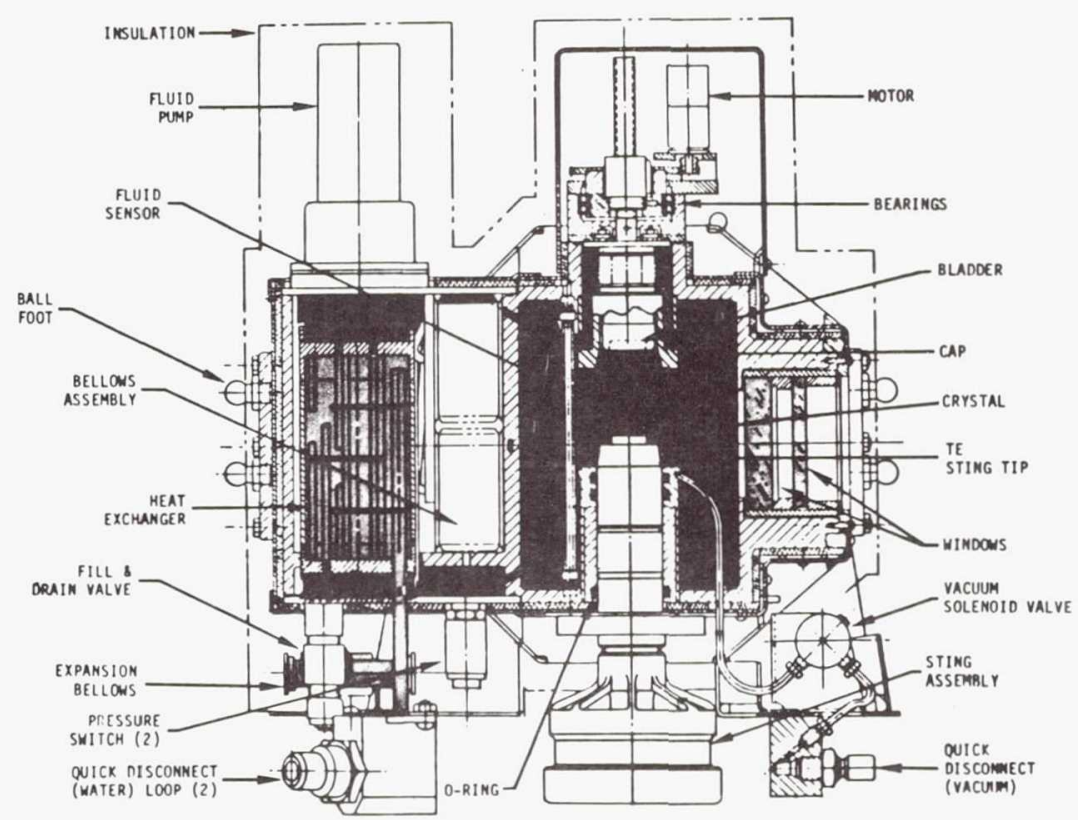

(b) TEST CELL DETAIL.

FIGURE 21. - FLUIDS EXPERIMENT SYSTEM (FES). 


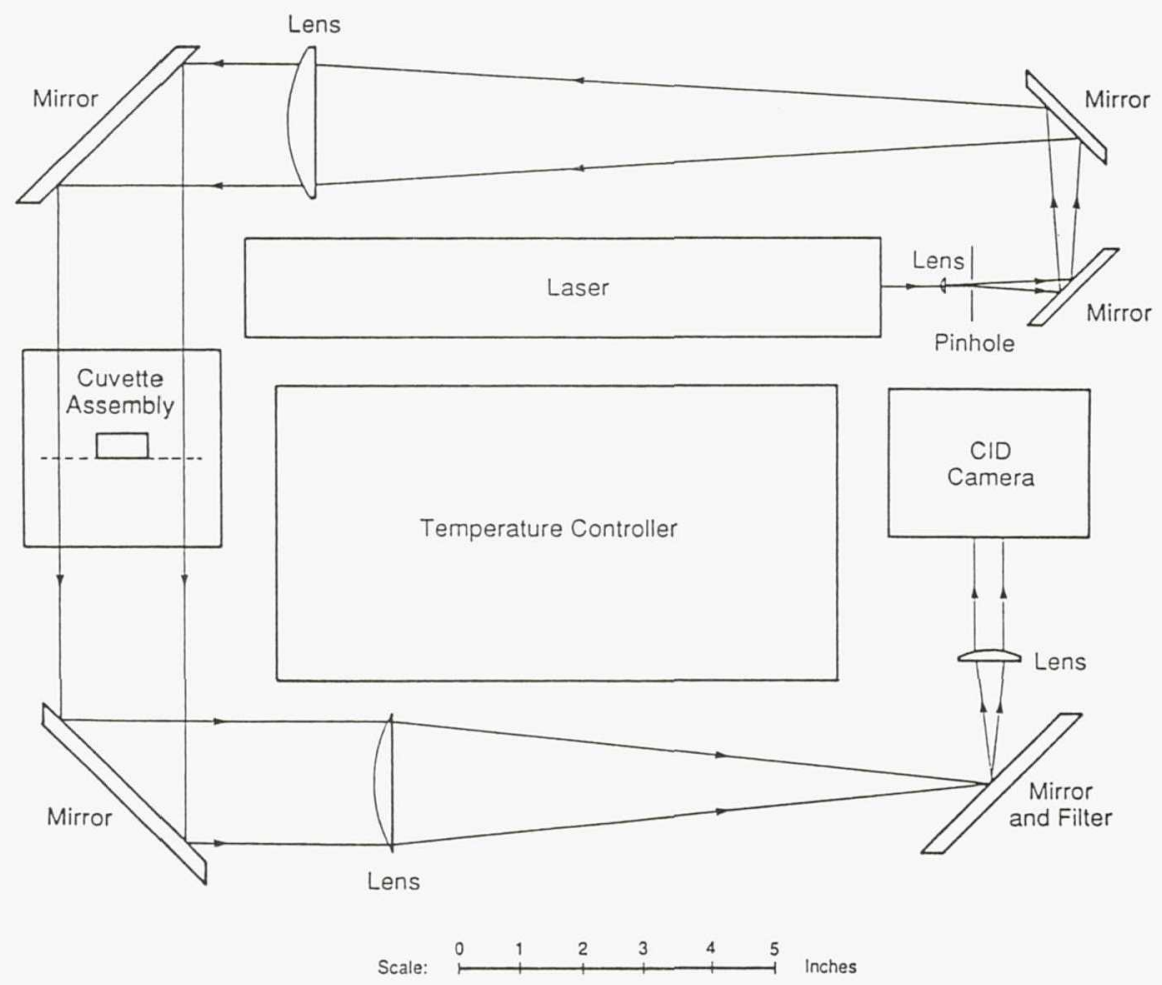

(a) CUVETTE IN RELATION TO FES OPTICS BENCH.

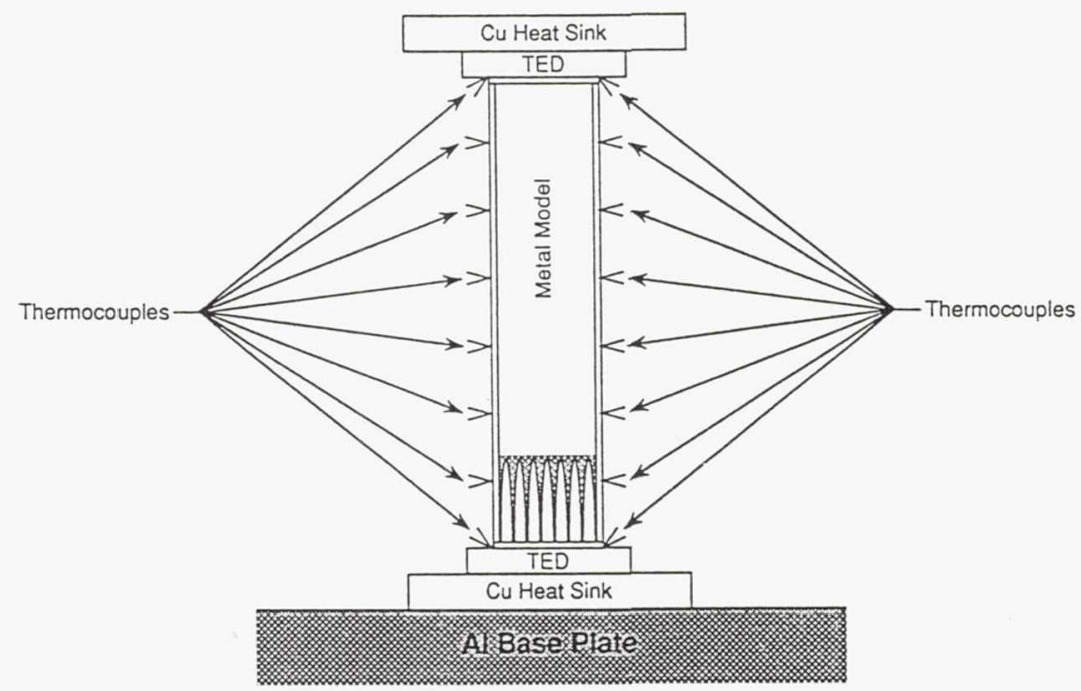

(b) DETAILS OF CUVETTE .

FIGURE 22. - CASTING AND SOLIDIFICATION TECHNOLOGY (CAST) EXPERIMENT. 

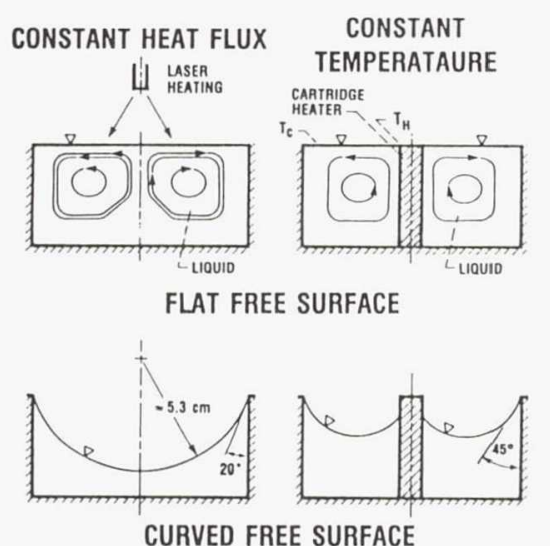

SPACE EXPERIMENT CONFIGURATIONS

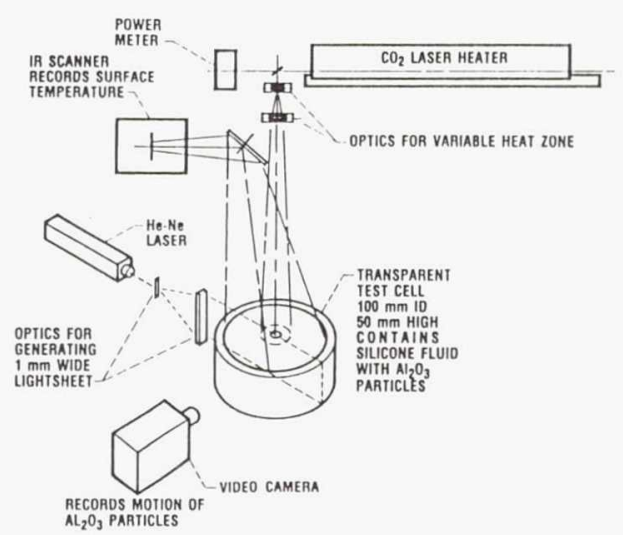

LABORATORY AFPARATUS SCHEMATIC

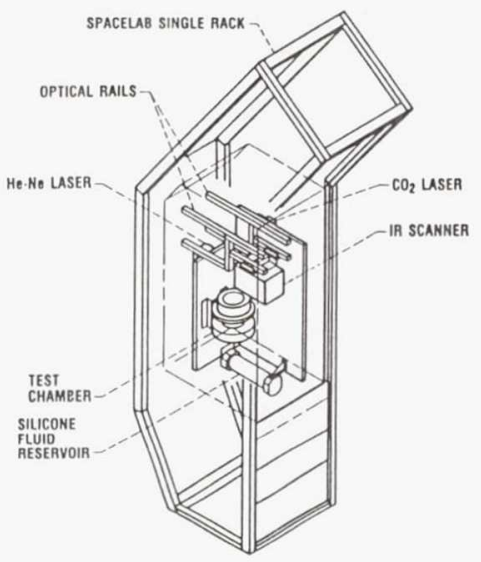

SPACE EXPERIMENT APPARATUS

FIGURE 23. - SURFACF TENSION DRIVEN CONVECTION EXPERIMENT (STDCE)/SPACELAB.
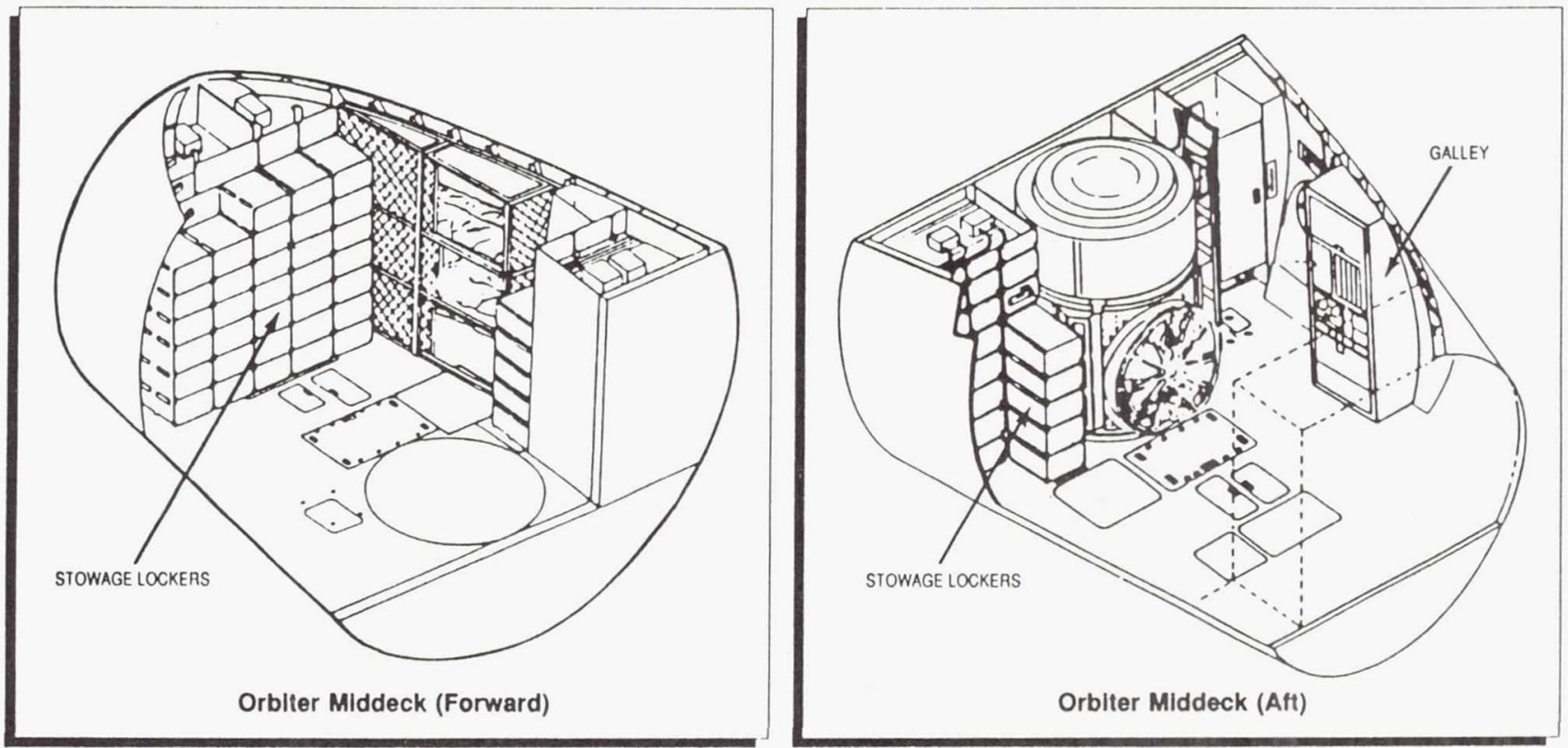

FIGURE 24. - MIDDECK FACILITY ON SPACE SHUTTLE. 

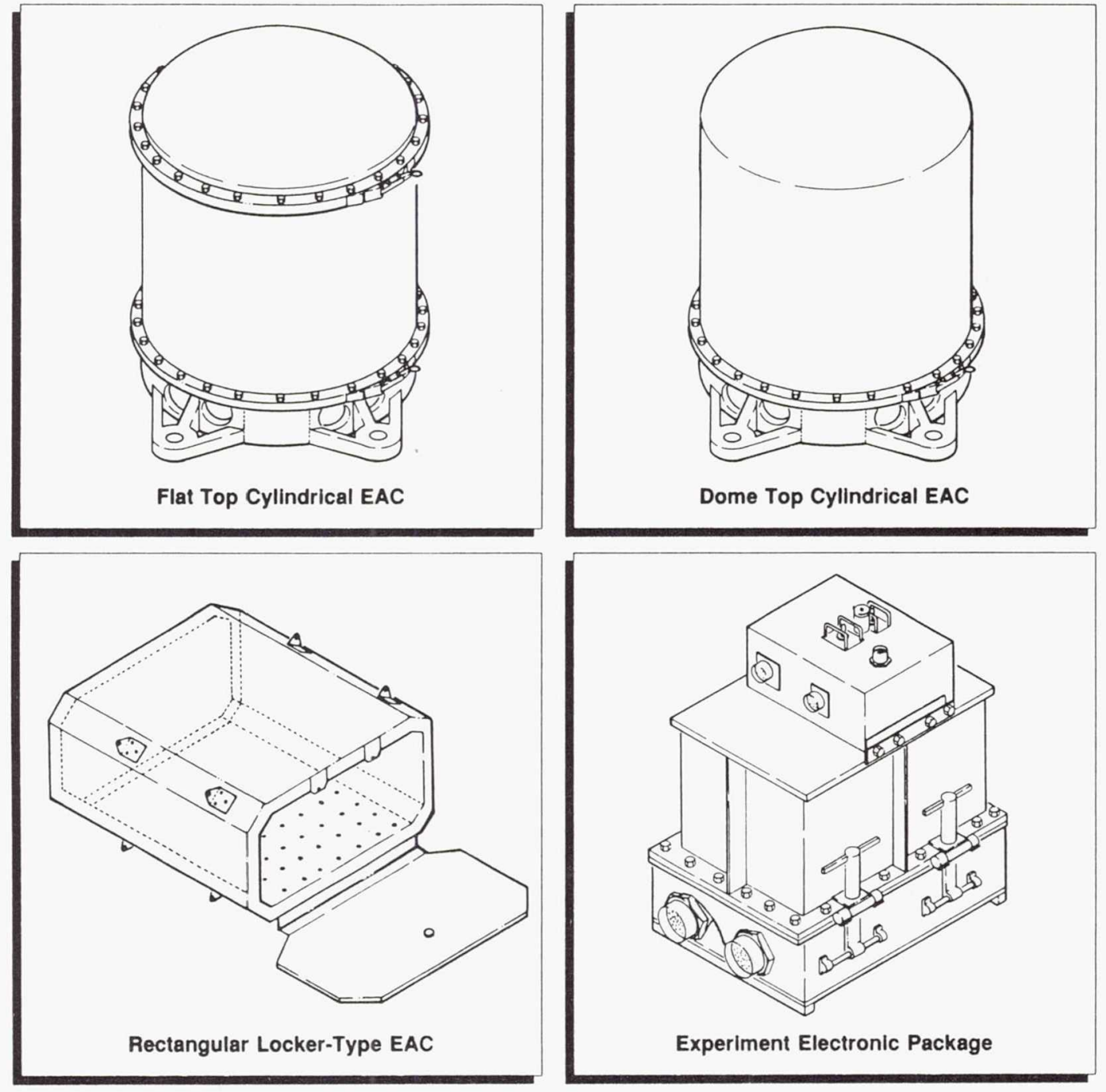

FIGURE 25. - EQUIPMENT APPARATUS CONTAINER (EAC) CONFIGURATIONS FOR SPACE SHUTTLE MIDDECK FACILITY. 


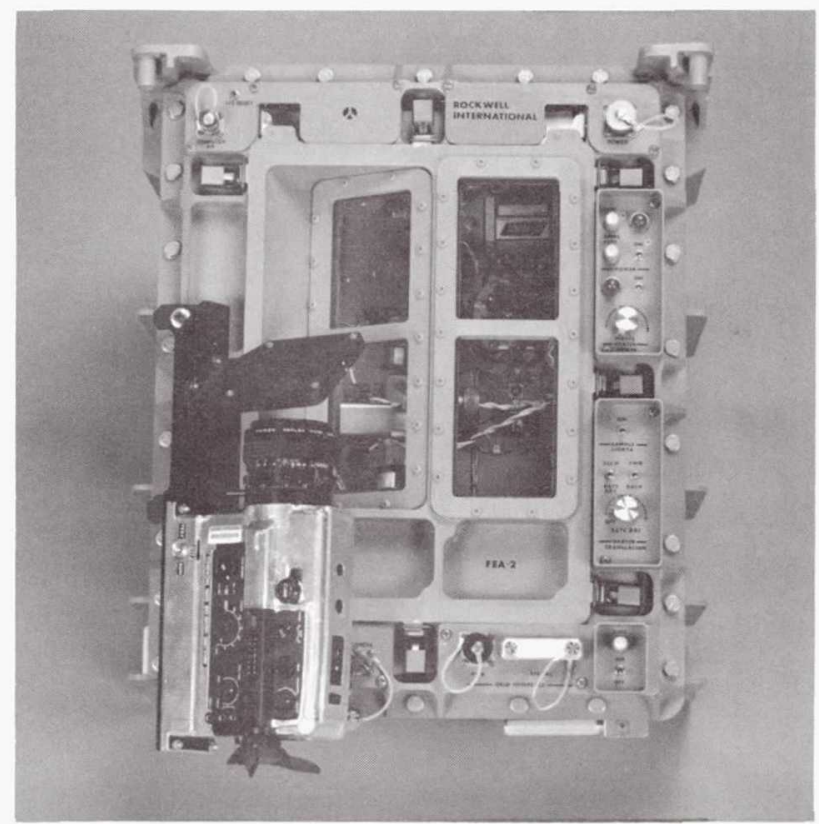

(a) TOP VIEW,

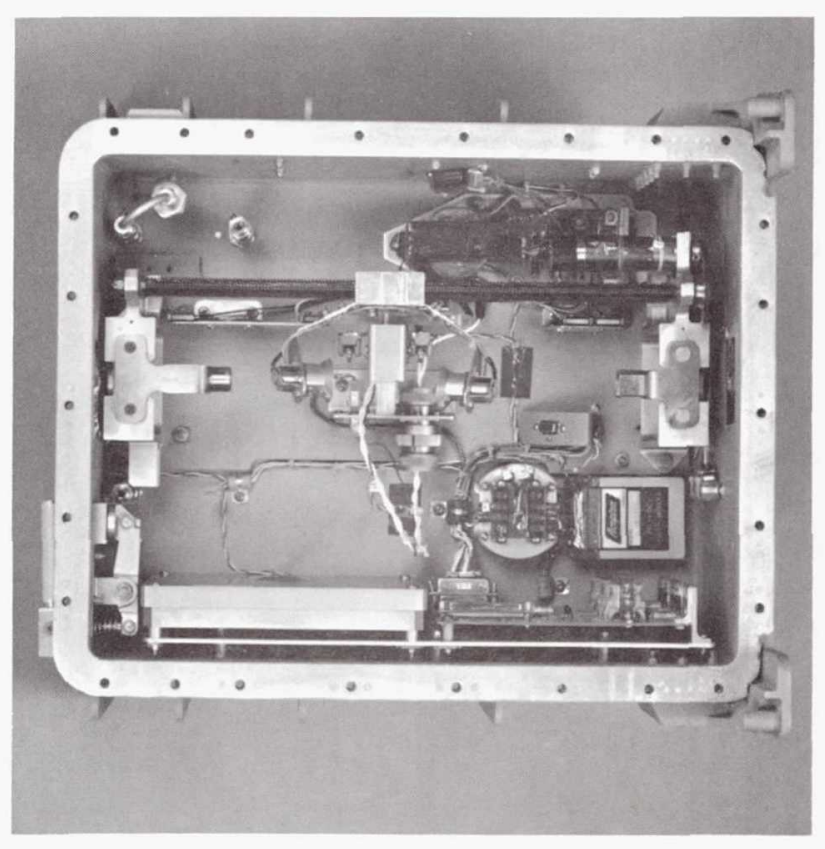

(b) TOP VIEW WITHOUT PLATE.

FIGURE 26. - FLUID EXPERIMENT APPARATUS (FEA). 


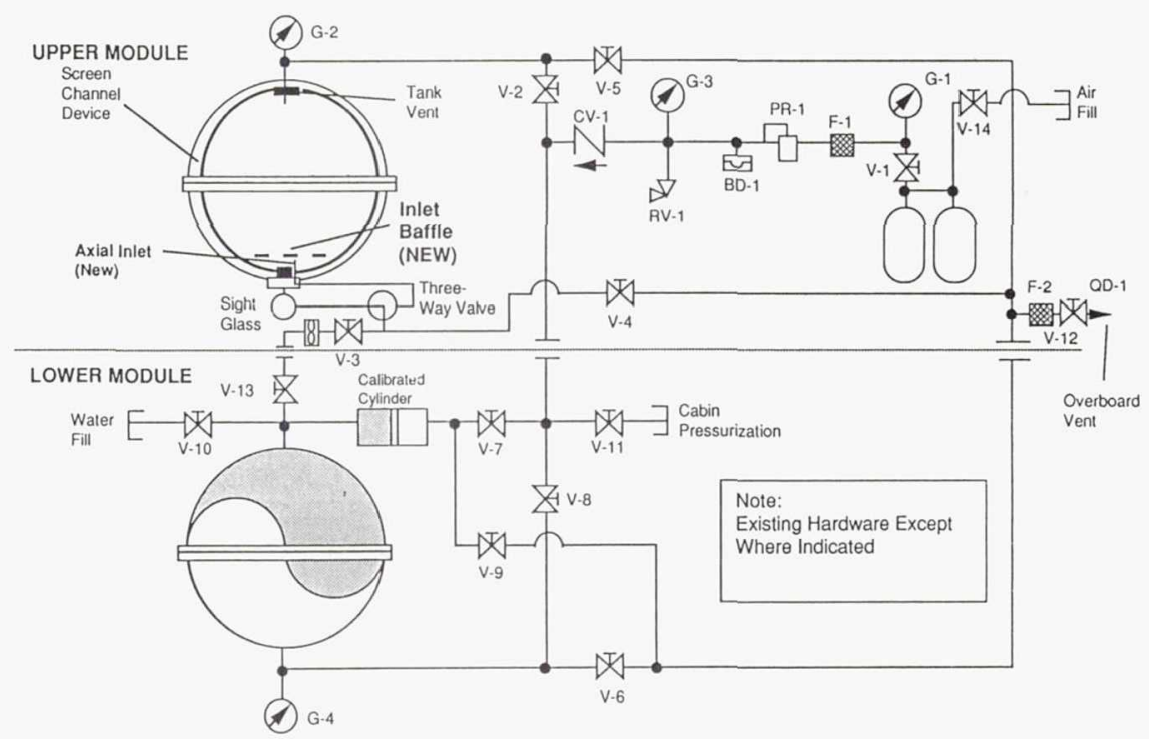

(a) PLUMBING SCHEMATIC.

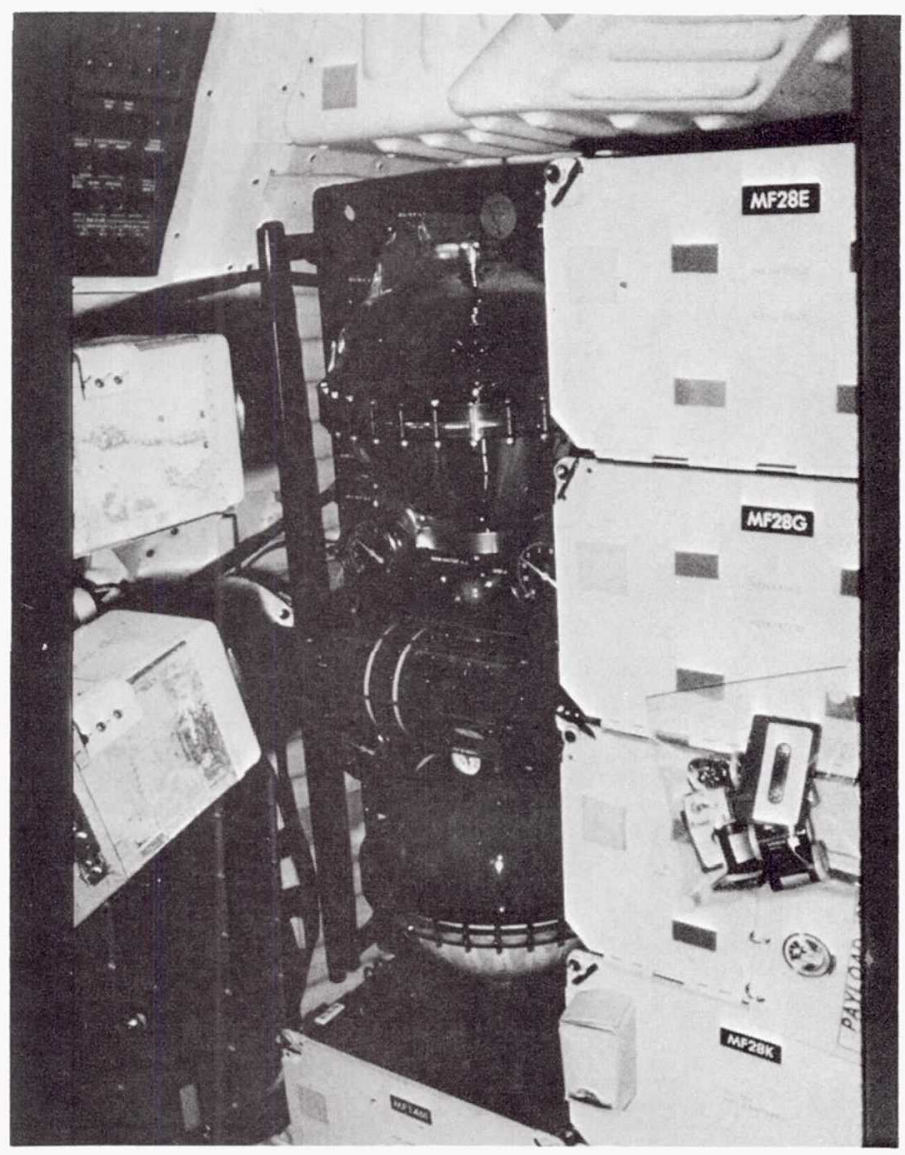

(b) FLIGHT HARDWARE IN RACK.

FIGURE 27. - STORABLE FLUID MANAGEMENT DEMONSTRATION (SFMD) FLIGHT 1. (FROM MARTIN MARIETTA. ) 


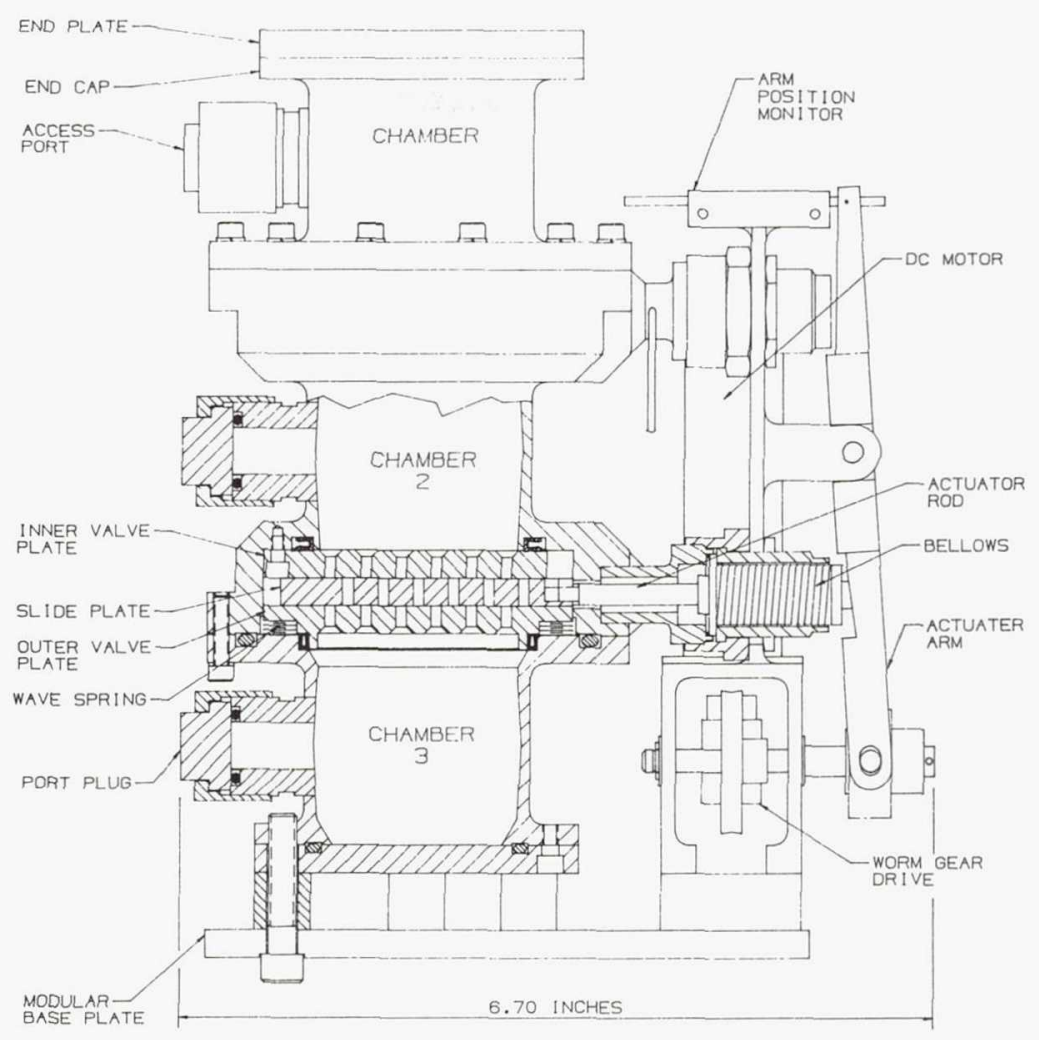

FIGURE 28. - CELL SCHEMATIC OF DIFFUSION MIXING OF ORGANIC SOLUTIONS (DMOS) EXPERIMENT HARDWARE.

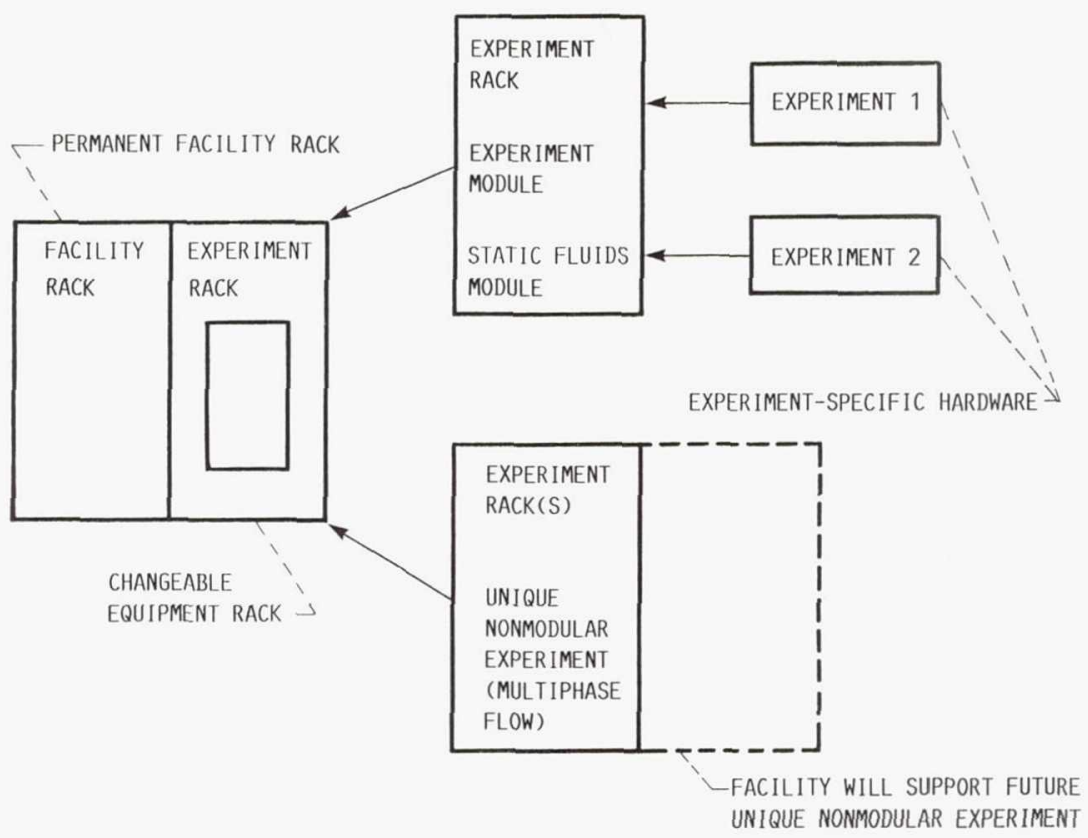

FIGURE 29. - MODULAR CONCEPT FOR FLUID PHYSICS/DYNAMICS FACILITY. (FROM REFERENCE 2.) 

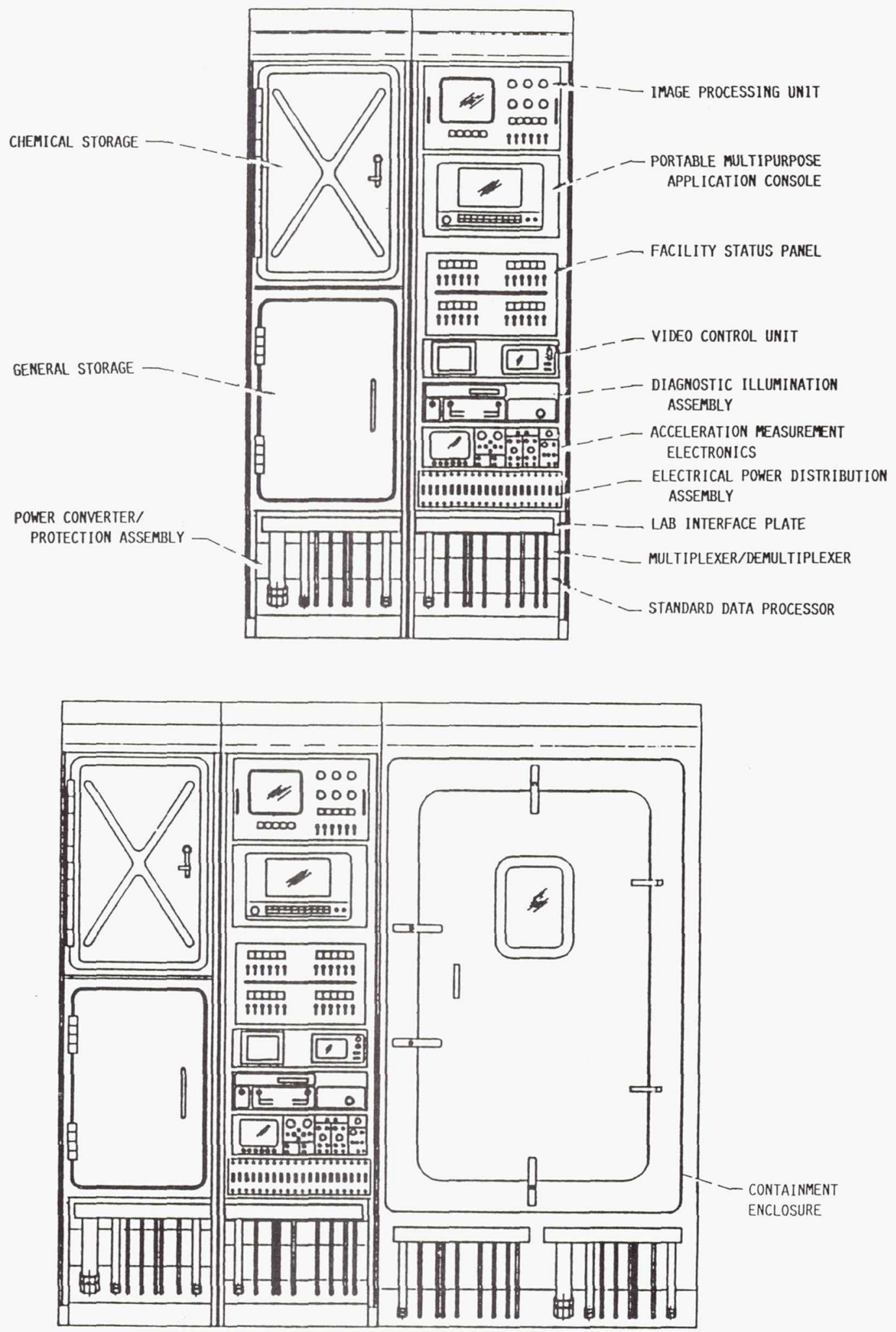

FIGURE 30. - FLUID PHYSICS/DYNAMICS FACILITY. (FROM REFERENCE 2.) 


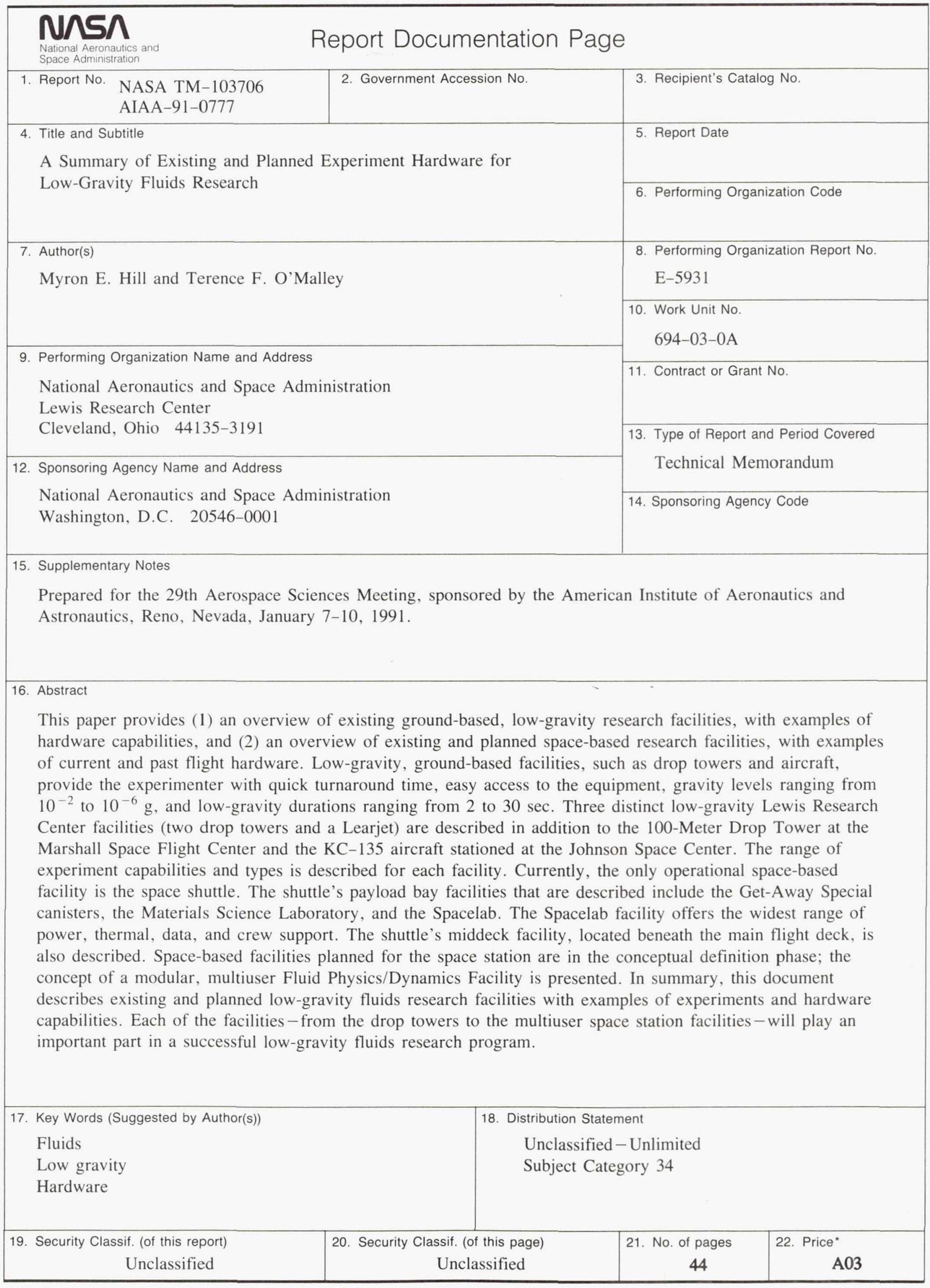

